Winter 12-20-2019

\title{
Caregiver Perspectives on Telehealth: A Service Delivery for Occupational Therapy
}

\author{
Rebecca Johnston \\ University of St. Augustine for Health Sciences
}

DOI: https://doi.org/10.46409/sr.SMLR2770

Follow this and additional works at: https://soar.usa.edu/capstones

Part of the Occupational Therapy Commons, and the Pediatrics Commons

\section{Recommended Citation \\ Johnston, R. (2019). Caregiver Perspectives on Telehealth: A Service Delivery for Occupational Therapy. [Doctoral project, University of St Augustine for Health Sciences]. SOAR @ USA: Student Capstone Projects Collection. https://doi.org/10.46409/sr.SMLR2770}

This Capstone is brought to you for free and open access by the Student Research at SOAR @ USA. It has been accepted for inclusion in Student Capstone Projects by an authorized administrator of SOAR @ USA. For more information, please contact soar@usa.edu, erobinson@usa.edu. 


\section{CAREGIVER PERSPECTIVES ON TELEHEALTH:}

\section{A SERVICE DELIVERY FOR OCCUPATIONAL THERAPY}

by

Rebecca E. Johnston

A Capstone Presented in Partial Fulfillment

of the Requirements for the Degree of

DOCTOR OF OCCUPATIONAL THERAPY

University of St. Augustine for Health Sciences

December 2019 


\title{
CAREGIVER PERSPECTIVES ON TELEHEALTH:
}

\section{A SERVICE DELIVERY FOR OCCUPATIONAL THERAPY}

by

\author{
Rebecca E. Johnston
}

has been approved

December 2019

APPROVED:

Susan MacDermott, OTD, OTR/L, Doctoral Coordinator

Becki Cohill, OTD, OTR/L, Doctoral Coordinator

Erin Schwier, EdD, OTD, OTR/L, Program Director

ACCEPTED AND SIGNED:

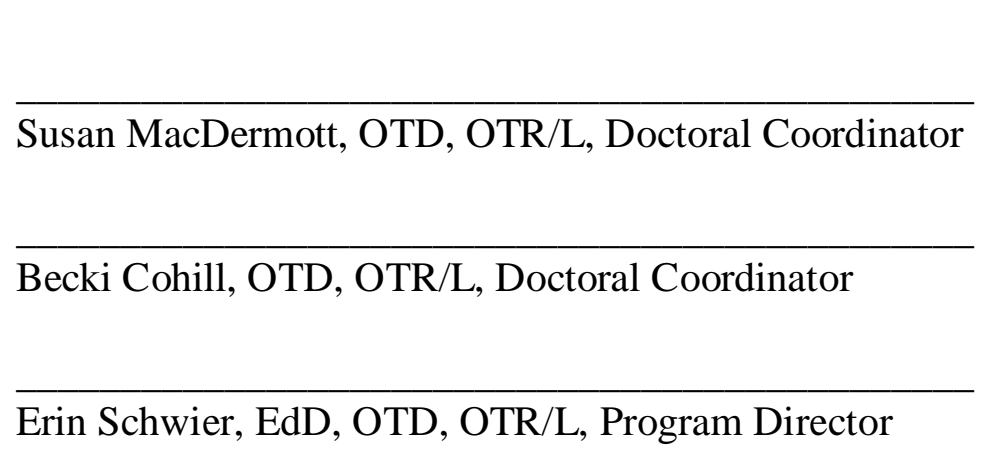


Table of Contents

$\begin{array}{ll}\text { CHAPTER I. Introduction } & 5\end{array}$

$\begin{array}{ll}\text { Background } & 5\end{array}$

$\begin{array}{ll}\text { Statement of Problem } & 6\end{array}$

$\begin{array}{ll}\text { Purpose Statement } & 6\end{array}$

$\begin{array}{ll}\text { Rationale for Proposed Project } & 7\end{array}$

$\begin{array}{lr}\text { Significance of Proposed Project } & 8\end{array}$

$\begin{array}{lr}\text { Preliminary Project Objectives } & 9\end{array}$

$\begin{array}{ll}\text { Assumptions } & 10\end{array}$

$\begin{array}{ll}\text { Limitations and Delimitations } & 10\end{array}$

$\begin{array}{ll}\text { CHAPTER II. Literature Review } & 11\end{array}$

Telehealth as a Service Delivery 11

$\begin{array}{ll}\text { Perceptions of Telehealth } & 11\end{array}$

$\begin{array}{ll}\text { Parent Coaching Model } & 12\end{array}$

CHAPTER III. Proposed Methods 12

$\begin{array}{ll}\text { Participants } & 12\end{array}$

$\begin{array}{ll}\text { Materials } & 13\end{array}$

$\begin{array}{ll}\text { Design } & 14\end{array}$

$\begin{array}{ll}\text { Procedures and Timelines } & 15\end{array}$

CHAPTER IV. Actual Methods 16

$\begin{array}{ll}\text { Participants and Materials } & 16\end{array}$

$\begin{array}{ll}\text { Procedures and Timelines } & 17\end{array}$ 
$\begin{array}{lr}\text { CHAPTER V. Results and Analysis } & 18\end{array}$

$\begin{array}{lr}\text { Caregivers without Telehealth Experience } & 18\end{array}$

Caregivers with Telehealth Experience $\quad 23$

$\begin{array}{ll}\text { CHAPTER VI. Discussion } & 27\end{array}$

$\begin{array}{ll}\text { Limitations } & 27\end{array}$

$\begin{array}{ll}\text { Future Research } & 28\end{array}$

$\begin{array}{ll}\text { Implications for Occupational Therapy } & 29\end{array}$

$\begin{array}{ll}\text { Conclusion } & 29\end{array}$

$\begin{array}{ll}\text { References } & 31\end{array}$

Appendix A: Script for Recruitment and Participant Outreach 34

Appendix B: Survey Questions- Caregivers with Telehealth Experience 40

Appendix C: Survey Questions- Caregivers without Telehealth Experience 43

Appendix D: Interview Questions- Caregivers with Telehealth Experience 46

Appendix E: Interview Questions- Caregivers without Telehealth Experience 47

Appendix F: San Diego Regional Center PowerPoint Presentation and Handouts 48

Appendix G: HM Systems PowerPoint Presentation and Handouts 53 


\section{CHAPTER I. Introduction}

\section{Background}

Telehealth; also known as telerehabilitation, telecare, telemedicine, teletherapy, and telepractice; is an emerging healthcare service that is utilized in various healthcare facilities with a span of ages, conditions, and locations (World Federation of Occupational Therapy [WFOT], 2014). Telehealth utilizes information and communication technologies to deliver services to a patient when the healthcare provider is not in the same location (WFOT, 2014). Telehealth can provide an online platform for evaluations, consultations, monitoring, supervision, and intervention with patients and other professionals (WFOT, 2014).

Telehealth is an emerging method of delivering occupational therapy (OT) services to various populations, including: children and youth; productive aging; health and wellness; mental health; rehabilitation, disability, and participation; work and industry (Cason, Hartmann, Jacobs, \& Richmond, 2013). Occupational therapists use telehealth to "develop skills; incorporate assistive technology and adaptive techniques; modify work, home, or school environments; and create health-promoting habits and routines" (Cason et al., 2013, p. 69). Telehealth is beneficial because it increases accessibility of services, increases access to specialists and/or providers, increases client and therapist flexibility of treatment times, reduces travel time, and reduces delays in service by allowing for online consultation (Cason et al., 2013; Gardner, Bundy, \& Dew, 2016; Kairy, Lehoux, Vincent, \& Visintin, 2009).

Telehealth will be investigated in this project with the population of caregivers of children receiving early intervention (EI) services. Early intervention services "promote the development of skills and enhance the quality of life in infants and toddlers who have been identified as having a disability or developmental delay, enhance capacity of families to care for 
their child with special needs, reduce future educational costs, and promote independent living" (Cason, Behl, \& Ringwalt, 2012, p. 1). Using telehealth to deliver EI services helps to improve access to care in underserved areas (Cason et al., 2012). Telehealth also promotes "interdisciplinary collaboration, coordinated care, and consultation with specialists" who are not normally available in these underserved communities (Cason et al., 2012).

\section{Statement of the Problem}

There are many benefits that telehealth offers to clients and healthcare providers (Baharay \& Reiser, 2010). Specific to occupational therapy, telehealth provides benefits such as: increased clinical outcomes compared to traditional methods of care, increased participation, and increased time for consultations (Kairy et al., 2009). However, as a newer service delivery, some clients and healthcare professionals have reservations about telehealth and as such, this method of care is not being utilized to its fullest potential (Schaper \& Pervan, 2007). In addition, there is a gap in the literature regarding experiences of those who have participated in a telehealth program. Additional research on effectiveness of telehealth, overall experiences of clients involved in receiving telehealth services, and education to healthcare providers is necessary to increase awareness and utilization of this service model (Irfanahemad, Nandakumar, \& Radhiki, 2018; Kessler \& Graham, 2015).

\section{Purpose Statement}

The purpose of this capstone project is to investigate the experiences and perceptions of caregivers regarding telehealth. Specifically, the project will examine the experiences of caregivers of children who have engaged in an early intervention telehealth OT program, as well as caregivers who have engaged in early intervention OT services without telehealth involvement. Caregivers can include any adults who are involved in the well-being of a child and 
are familiar with the therapy service the child is receiving. This mixed-methods research study will examine the effectiveness and viability of telehealth as a service model and will identify potential strengths, weaknesses and solutions to challenges that can be implemented in future programs.

\section{Rationale for Proposed Project}

Early intervention services via telehealth utilize the model of coaching. Coaching involves the service provider and client collaboratively identifying challenges, setting goals and working towards those set goals (Graham, Rodger, \& Ziviani, 2013). Telehealth in the EI setting often uses this effective, client-centered approach of educating caregivers and treating the child collaboratively (Graham et al., 2013). Evidence has shown that this approach is effective in promoting parent-child interactions, caregiver efficacy, carryover of services, caregiver responsiveness to the child, participation of the child, and occupational performance (Graham et al., 2013; Little et al., 2018). The coaching model can help to highlight the effectiveness of telehealth in EI and can help make telehealth an option to other healthcare providers and families in need.

Overall, telehealth is an underused service that can benefit many individuals in need of occupational therapy. Currently, this service has not been universally accepted by healthcare providers and clients. The unified theory of acceptance and usage of technology model can help explain reasons for pushback regarding telehealth in order to implement potential solutions to promote acceptance of this service delivery (Schaper \& Pervan, 2007). The model suggests that technology usage is influenced by four main constructs: performance expectancy, effort expectancy, social influence, and facilitating conditions (Schaper \& Pervan, 2007). Identifying solutions to barriers regarding technology platforms being used for telehealth services and 
improving the ease of use for clients and therapists will satisfy the first two constructs of performance expectancy and effort expectancy (Schaper \& Pervan, 2007). This research will influence the third construct of social influence by supplying information to the community of healthcare providers and their clients regarding the effectiveness of telehealth and providing solutions to potential barriers for future programs. The facilitating conditions can be influenced by examining the parameters of the EI telehealth program and how the service providers were trained prior to delivering OT services via telehealth (Schaper \& Pervan, 2007; Irfanahemad et al., 2018).

This research will highlight outcomes of those who received telehealth services and will describe the experiences of clients involved. It will enhance knowledge to provide solutions to possible limitations of the telehealth program and/or limitations that participants identified to support future programs. This is essential to continue to expand occupational therapy outreach in EI and across various populations via a virtual context.

\section{Significance of Proposed Project}

This project will provide perspective to the gap in literature on caregiver experiences with and their acceptance of telehealth as a service model. It will explore both the experiences of caregivers who have experience with telehealth, as well as those without telehealth involvement. In addition, the project will gather data on the growing EI telehealth program and will investigate its local impact. The reported perceptions from caregivers and feedback from the telehealth program can help to identify strengths and barriers that can be addressed in other telehealth programs. This data can also help to influence how EI healthcare providers deliver telehealth services. This study will help to improve awareness of telehealth to both healthcare providers 
and future clients in order to reach additional people in need of occupational therapy services.

\section{Preliminary Project Objectives}

1) Describe parameters of the EI telehealth program, the current methods of intervention, and outcomes currently measured.

2) Identify perspectives of caregivers who are participants of an EI telehealth program through a mixed-methods survey and a qualitative interview.

3) Identify perspectives of caregivers who have not used telehealth on their potential use of telehealth through a mixed-methods survey and a qualitative interview.

4) Analyze findings from the survey and interviews. The survey will ask quantitative questions to gather information about demographics and experiences with and perceptions of telehealth. The interview will include open-ended, qualitative questions to gather detailed narratives regarding participants' acceptance and experiences with telehealth as a service model.

5) Outline strengths and limitations of telehealth, through the experiences of caregivers involved in the EI program, to propose recommendations to future telehealth programs, therapists and potential clients. From these perspectives, create an educational presentation for service coordinators and service providers looking to expand services to include telehealth.

6) Summarize findings to describe client experiences and perceptions of telehealth to highlight effectiveness of telehealth to improve acceptance of the service model and to promote outreach of OT services. Identify strengths, challenges, and solutions to telehealth in order to support other programs. 


\section{Assumptions}

The assumptions of this study are that participants have access to technology and understand how to use the same online platform that was utilized for previous telehealth sessions. Some families might have faced challenges with technology and access to a computer previously; any barriers or technological issues need to be considered prior to conducting interviews or before administering the surveys. In addition, there is the assumption that participants are willing to discuss their experiences. To overcome this potential challenge, various methods of interviews and surveys may be more appropriate for different families. Openended questions will be necessary to gather as much information as possible and the methods of questioning will be tailored to each participant

\section{Limitations and Delimitations}

A limitation of the study is that there may be technological issues such as: internet connectivity, computer literacy, or problems with the online communication platform itself. In addition, the timing for individuals to discuss their experiences will be limited and based on their personal schedule. Consistency in participation can fluctuate, depending on the family's availability and free time. Delimitations of the study are that the study will focus on the population of early intervention and telehealth. Caregivers of children in an EI program will be included, but other individuals involved in the care and development of the child will not be included in the study. In addition, this project will utilize a mixed-methods approach to gather data through use of interviews and surveys. The study will examine the overall experiences of participants and open-ended questions will be necessary in the interview to understand individual narratives. Therefore, information gathered will be limited to qualitative data from the interviews, and quantitative data from the surveys. 


\section{CHAPTER II. Literature Review}

There are several themes in the literature regarding telehealth and how it is being practiced and perceived in the early intervention settings. The themes that will be discussed include: telehealth as a service model, perceptions of telehealth, and the parent coaching model. These themes help to drive the direction of the capstone project and provide insight to the topics that will be examined in further detail.

\section{Telehealth as a Service Delivery}

Occupational therapists can use telehealth in many settings, including: pediatrics, health and wellness, mental health, rehabilitation, ergonomics, disability, and geriatrics (Cason et al., 2013). In these settings, evidence has highlighted the effectiveness of the service in terms of outcomes; it is equal to, if not more effective than, traditional in-person therapy (Cason, 2014). In addition to benefits of telehealth, this emerging practice can also alleviate provider shortages, decrease cost, and allow for care to take place in the natural environment of the family (Zylstra, 2013). There is also clear support for telehealth as a service delivery in pediatric intervention (Little, Wallisch, Pope \& Dunn, 2018; Zylstra, 2013).

\section{Perceptions of Telehealth}

In the literature, there are common themes regarding the experiences and perceptions of individuals who participated in a telehealth program. Individuals from various age groups and populations found that it was a positive and effective service that helped to address barriers to care (Gardner et al., 2016). Benefits identified by participants included the following themes: it was straightforward, it increased access to healthcare, it improved self-management, it reduced costs, it allowed for flexibility of scheduling, and it reduced travel time (Ashburner, Vickerstaff, Beetge, \& Copley, 2016). However, many participants disclosed challenges with telehealth, 
such as: it was not as personal as in-person services, and there were many technical difficulties (Gorst, Armitage, Hawley, \& Coates, 2013). Overall, perceptions of telehealth from the standpoint of the clients receiving care were high, but there are still some challenges that need to be addressed in order to improve telehealth acceptance and quality of care through this model.

\section{Parent Coaching Model}

In the early intervention setting, either parent training, or parent coaching, is necessary for the continuation of care and development of the child. Coaching involves collaboratively setting goals with the client and helping to outline a plan to achieve these outcomes (Kessler \& Graham, 2015). Therapists often use the coaching model in EI telehealth therapy, as it is important to promote both caregiver involvement and caregiver effectiveness in the treatment of the child (Graham et al., 2013). Coaching via telehealth helps to promote caregiver self-efficacy, encourage carryover of services, and ensure child safety (Little et al., 2018). Caregivers have reported that parent coaching is a beneficial service that promotes self-efficacy, improves occupational performance of the child, and increases participation of the child (Graham et al., 2013; Little et al., 2018). Additional research using larger sample sizes and more vigorous research methods should be conducted to increase the body of knowledge and further recommend this service to clinicians and appropriate families (Kessler \& Graham, 2015).

\section{CHAPTER III. Proposed Methods}

\section{Participants}

This study will investigate perceptions of telehealth of caregivers, or individuals responsible for the care of young children. Both caregivers of children with telehealth experience, as well as caregivers of children with no telehealth experience, will be included. The lead occupational therapist of the EI telehealth program will gather contact information from the 
caregivers. Participants will be recruited by asking for their participation through email, and consent will be assumed by their engagement in the project. In addition, caregivers engaged in EI services without telehealth will be recruited through convenience sampling. They will be asked to participate in the study and their consent will be verbal. Ideally, twenty-five caregivers with telehealth experience will be willing to participate and twenty-five caregivers who have no experience with telehealth will also participate. The sample population will be comprised of fifty participants to increase statistical strength and increase generalizability of the research findings as well as to gather data that will be more representative of the population of caregivers of children receiving EI services.

\section{Materials}

The email script (Appendix A) sent to caregivers in the telehealth program will describe and explain the significance of the study. Attached to the email will be a link to a ten-minute quantitative survey which will be used to gather information regarding age of the child, length of services the child received, perceived strengths and barriers to telehealth, and overall perceptions of experiences with telehealth. Following the survey, participants will be asked to engage in an interview on an online videoconferencing platform to gather additional qualitative information. The interview will gather detailed supplementary information to later identify shared themes in the experiences. The interview will take thirty minutes to complete and requires that the participants are able to use an online communication platform. The audio files will be recorded by the researcher on a password protected computer and password protected account on the computer. The audio files will be transcribed, coded for themes in the narratives, and deleted. See Appendix B and D for the survey and interview questions for caregivers involved in the EI telehealth program. 
Caregivers without telehealth experience who are involved in an in-person EI program will be handed a printed script that describes the significance of the study. The participants will agree to participate by supplying their email address to the researcher. The researcher will then email a link to a quantitative survey that should take approximately ten minutes for participants to complete. A second email will be sent asking for further participation in a thirty-minute qualitative interview. The interview will also take place over an online communication platform, the audio files will be recorded and transcribed, and deleted from the account. The questions will cover demographic information and will assist the researcher's investigation on the caregivers' understandings and perceptions of telehealth. The data from the interview will help to identify reasons why participants may have chosen not to engage in telehealth, or why they do not have access to a telehealth program. See Appendix $\mathrm{C}$ and $\mathrm{E}$ for the survey and interview questions for caregivers without telehealth experience.

\section{Design}

The mixed-methods study will gather open-ended data to understand experiences of participants through their own words. Qualitative data will be important to later identify commonalities in the narratives. Qualitative data helps researchers understand experiences from the participant's point of view and helps them to develop patterns and theories from the information gathered (Smith, 2019). This study design will include survey and interview questions that are based on the Occupational Performance History Interview (OPHI), which consists of "a semi structured interview, scales for rating the information obtained in the interview, and a format for recording qualitative data" (Kielhofner, Mallinson, Forsyth, \& Lai, 2001, p. 261). The OPHI was chosen as a model by the researcher to guide questions and conversations with the participants. In addition, the researcher will gather quantitative data 
regarding number of participants, age of the children who participated, length of time the children received services, and a scale of caregivers' perceptions of telehealth. This data will be important to understand demographic factors in telehealth.

\section{Procedures and Timelines}

First, the researcher will observe occupational therapy sessions through an EI program facility called HM Systems to gain an understanding of the EI setting, family dynamics, role of OT in the home, and caregiver involvement in sessions. The EI services will be provided by therapists in the natural environment. This will take place over the first four weeks of the capstone experience and intermittently into the next few months (July-November). Then, the researcher will observe occupational therapy EI sessions via telehealth to learn about the parent coaching model and logistics of telehealth. This will take place intermittently throughout observations at HM Systems (September-November). Participant recruitment, and the surveys will be administered in September. Following the surveys, participants will be asked to participate in an interview, which will take place through October. Conclusions from the findings will be analyzed to identify common themes in the responses and potential barriers to benefit future telehealth programs. This process will take place after the interviews are completed, from October-December. Then, the researcher will present to HM Systems in December regarding the perceptions, benefits, and logistics of telehealth to help with the development of a telehealth program for their own facility. Lastly, all the information will be implemented into a final paper and presented at a poster presentation in December at University of Saint Augustine for Health Sciences. 


\section{CHAPTER IV. Actual Methods}

\section{Participants and Materials}

This study investigated caregivers' perceptions of telehealth. Nine caregivers who did not have experience with telehealth therapy services participated in the study by taking a mixedmethods survey through Google Forms. This survey was used to gather demographics and family living situations and asked about perspectives of telehealth. Additionally, two caregivers who engaged in a therapy program via telehealth participated as well. These participants took a separate mixed-methods survey through Google Forms that gathered demographics and family living situations, as well as experiences with telehealth and thoughts on how to improve the service. The eleven participants fit the criteria of being a caregiver of a child receiving EI therapy services. The participants were recruited using convenience sampling from their therapy provider.

The researcher began the capstone project by observing occupational therapy, physical therapy, and speech therapy EI sessions at HM Systems, as well as occupational therapy EI sessions via telehealth. The therapists at HM Systems provided the researcher with contact information for potential participants. Additionally, the lead occupational therapist of the EI telehealth program shared the survey with families who were willing to participate in the study and asked the families if they would be interested in engaging in a qualitative interview. One caregiver with telehealth experience participated in a thirty-minute interview to gather additional qualitative data in the form of a narrative. The interview took place over a phone call and the participant was asked initially for verbal consent to have the audio recorded for later reference. The audio files were recorded through a HIPAA compliant application called Otter Voice Meeting Notes. The audio file was recorded on a password protected computer and a password 
protected account; the name and contact information were completely confidential. The file was transcribed by the researcher and deleted.

In addition to recruiting through HM Systems and the occupational therapist of the EI telehealth program, the researcher also contacted different occupational therapists in the San Diego community who worked in the EI setting through phone calls, and through different Facebook forums. The Facebook groups included: Telehealth for Occupational Therapy, Pediatric Physical-Occupational-Speech Therapy Telehealth, Occupational Therapy in Telehealth, Colorado EI Telehealth Interest Group, EI Support and Share, and EI Occupational Therapists. These therapists provided contact information to families that they believed would be willing to participate in the study. The researcher contacted all the potential recruits from therapists in the community and Facebook by way of email or text, depending on the preferred method of contact. The message described the significance of the study, what would be expected if they were to participate, and included a link to the appropriate survey.

\section{Procedures and Timelines}

First, the researcher observed occupational therapy, physical therapy, and speech therapy sessions at HM Systems to gain an understanding of the evaluation and intervention process of the EI setting, as well as the family dynamics and levels of involvement of the caregivers. This took place over the first eight weeks of the capstone experience (July-October). During this time, the researcher also continued to develop an IRB for the capstone project before the research began. Then, the researcher observed occupational therapy EI sessions via telehealth to learn about the dynamics of telehealth and the parent coaching approach used in the evaluation and intervention process. This took place intermittently throughout the observations at HM Systems (September-November). Participant recruitment and surveys were administered from September 
to November and participant interviews took place in October. Conclusions from the findings were analyzed to identify common themes in the two groups of participants, as well as future application. This process took place after the surveys and interviews were completed (November-December). The researcher presented to the San Diego Regional Center and to HM Systems to discuss the benefits and barriers of telehealth, how to implement a telehealth program, and themes and conclusions from the findings regarding caregiver perceptions of telehealth as a service model for therapy. These two presentations took place in December. Lastly, all the information was integrated into the final capstone paper and was presented at a poster presentation at University of Saint Augustine for Health Sciences in December.

\section{CHAPTER V. Results and Analysis}

\section{Caregivers without Telehealth Experience}

Nine caregivers with no telehealth experience, and who had a child who was receiving EI therapy services, participated in this study. These individuals lived in various states including: California, Arizona, Colorado, Utah, and Massachusetts. These caregivers were recruited from therapists at HM Systems, as well as therapists in the community working in the EI setting. The children receiving services ranged from one month to thirty months of age, and they received services ranging from the span of one month to over one year. The children of the caregivers ranged in receiving one to multiple disciplines of occupational therapy, physical therapy, and speech therapy. Two caregivers of the nine knew about telehealth, while seven had never heard of the service. The demographics of the caregivers were widespread; however, common trends in perceptions of the service itself are outlined below. 


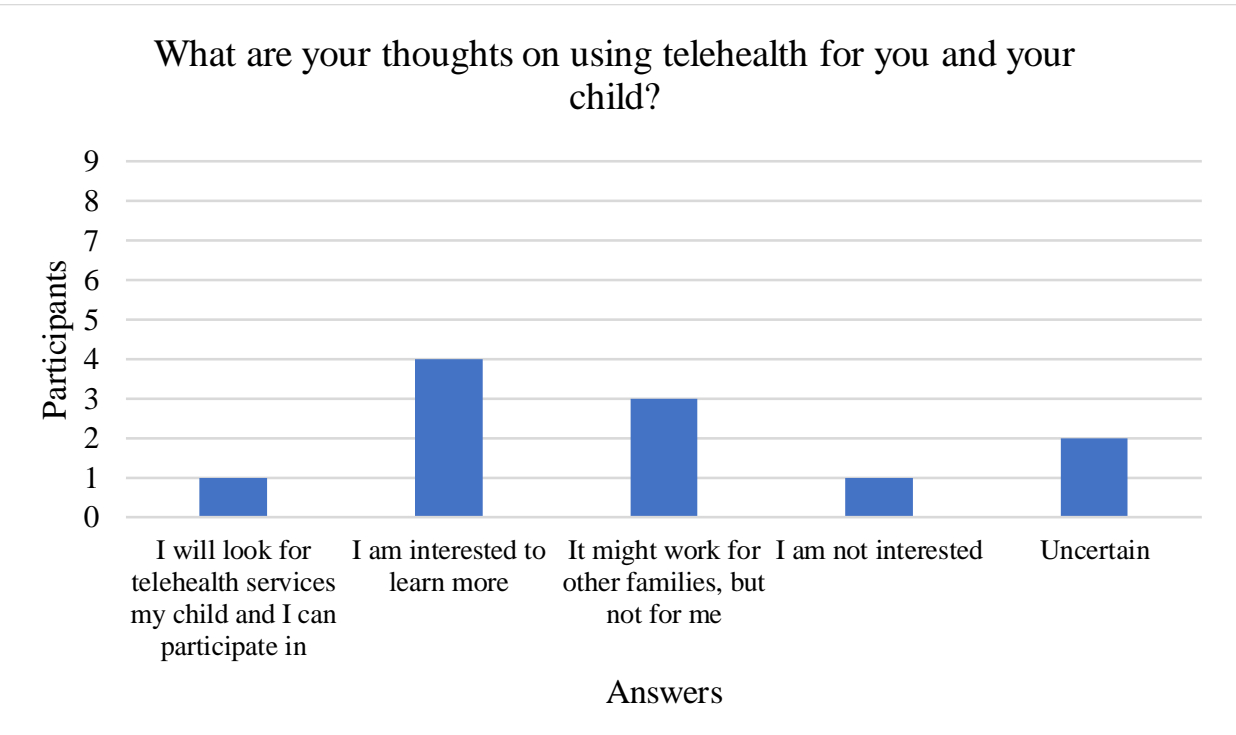

Figure 1. Survey answers from caregivers without telehealth experience regarding thoughts on telehealth as a service delivery model.

Before asking about the participant's view of telehealth, the service model was explained so that the participant understood the focus of the survey. The responses indicated that some families were interested in learning more about telehealth and others saw the value of telehealth but did not think it would be appropriate for their child's current therapy needs. When asked to explain, three participants stated that it would be helpful for families with transportation concerns, while two expressed the need for in-person therapy for a child who requires more hands-on, "involved treatment." One participant voiced concern about the "cost or insurance coverage, as well as choice of therapist" when potentially engaging in telehealth for therapy. Most caregivers indicated that telehealth could be beneficial as a supplemental session, but not as a replacement for in-person therapy services. 


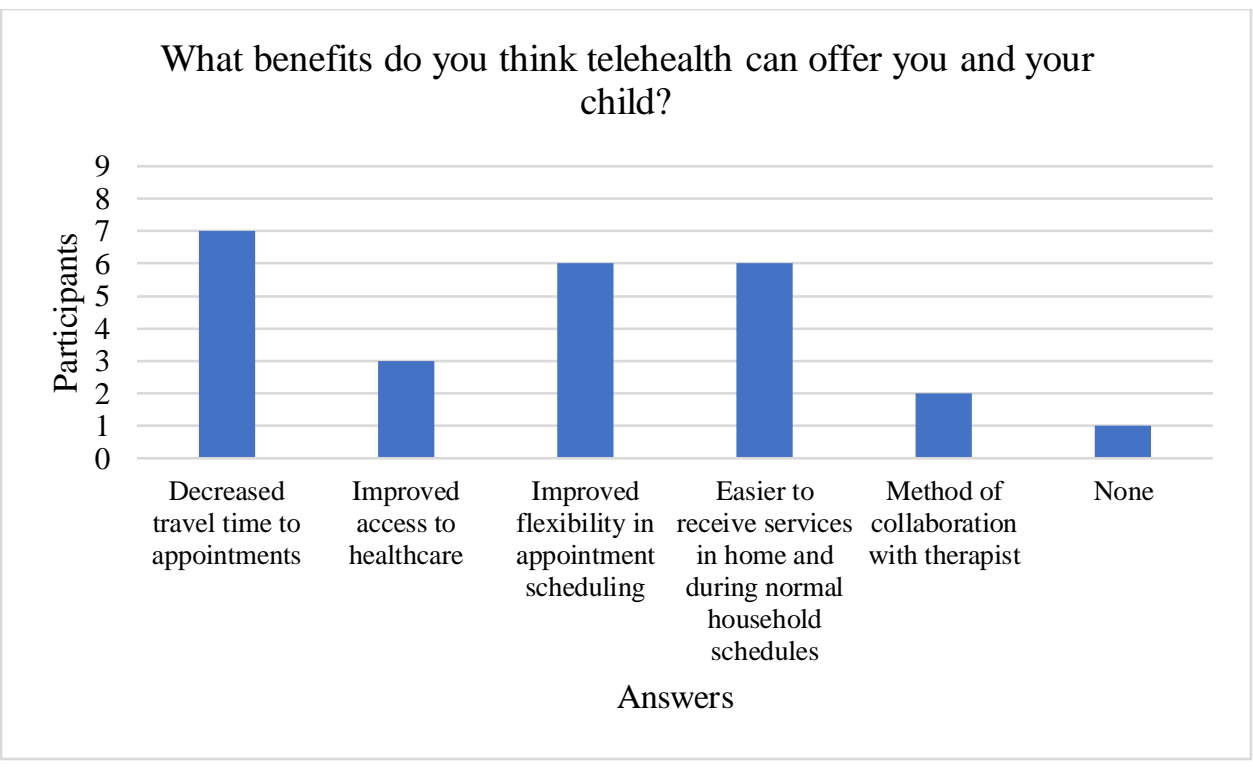

Figure 2. Survey answers from caregivers without telehealth experience regarding potential benefits telehealth can offer.

Generally, caregivers without telehealth experience were optimistic about the benefits that telehealth could potentially offer their family and child. The highest trends in responses regarding potential benefits of receiving EI services via telehealth included: decreased travel time to appointments, improved flexibility in scheduling appointments, and that it would be easier to receive care in the home and during their natural routines and schedules. 


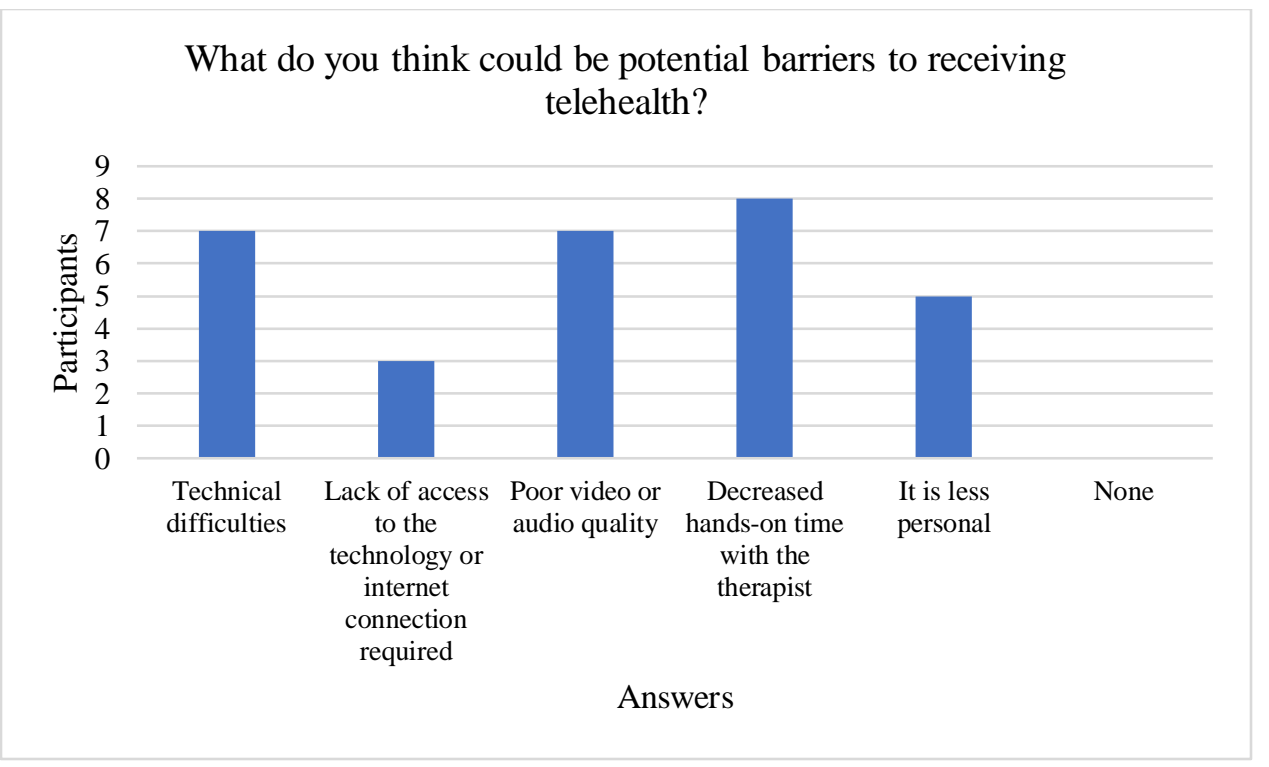

Figure 3. Survey answers from caregivers without telehealth experience regarding potential barriers of telehealth as a service delivery model.

The highest trends in responses regarding perceived barriers to receiving EI services via telehealth included: potential technical difficulties, poor video or audio quality, and decreased hands-on time with the therapist. In addition, a few caregivers stated that the lack of access to technology and that telehealth is less personal than in-person therapy could also be potential barriers to the service model. 
Would you be interested to try telehealth services for your child?

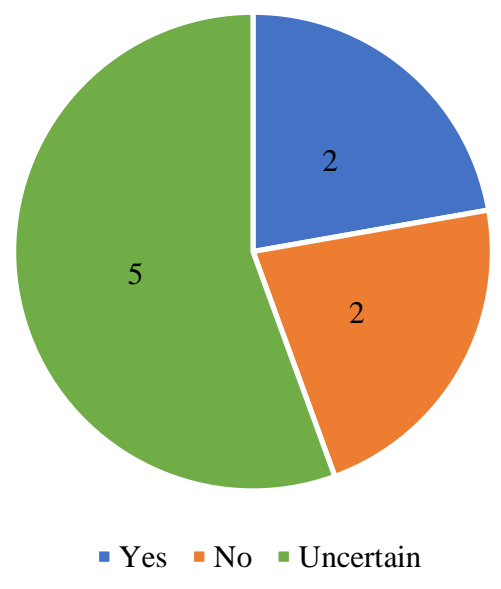

Figure 4. Number of caregivers without telehealth experience who would be interested to try telehealth for EI therapy.

Of the nine participants, five were uncertain on whether they would be interested to try telehealth. Two participants stated that they would be interested to try telehealth and two participants stated they would not want to try telehealth services. When asked to expand on their interest level in trying EI telehealth services, some participants expressed uncertainty with the effectiveness of the service as a replacement to in-person therapy and most individuals stated that they would prefer to have a combination of in-person sessions and telehealth sessions as the method of treatment. One participant expanded on this, stating that they would use telehealth "for consultations, for follow ups".

The responses suggested that most caregivers without telehealth experience were interested in telehealth, they recognized the benefits of what it could offer, and realized how it could be different from in-person services. However, most participants did not know much about telehealth, they were unaware of any local EI telehealth programs, and the general lack of awareness led to uncertainty in answers. Education on telehealth, case examples on when 
telehealth is appropriate to use, and the logistics of the service and responsibilities of the caregiver will help to improve the general understanding of the service model. This education can also include information on when using a mixed approach, of both telehealth sessions and inperson visits, is appropriate. In addition to this education, a push for program development will be essential for caregivers to see that this is an option for therapy and not just an addition to inperson services that are already occurring. Further explanations on parent coaching and parent involvement and empowerment can also help to allay the misconceptions that only cases that require minimal, "less involved" therapy, can benefit from telehealth. The general curiosity and openness of responses are encouraging for the acceptance of telehealth among caregivers with no telehealth experience; however, the general uncertainty of perceptions regarding this service model will need to be met with additional education to healthcare providers, communities, and families.

\section{Caregivers with Telehealth Experience}

There were two caregivers who participated in an EI telehealth program in Colorado who participated in the survey. One of these caregivers also engaged in an interview. These caregivers were recruited through the lead OT of the EI telehealth program. The children of the caregivers ranged from fourteen months to thirty-one months of age and have been receiving therapy services from four months to over one year. Both participants reported that the percentage of their child's therapy services were $76-100 \%$ via telehealth. The disciplines that the children received ranged from occupational therapy to speech therapy; however, the discussion will focus on their experiences with EI occupational therapy services via telehealth.

The participants' perceptions of telehealth were very positive. Both stated they will "continue to use it", and one said, "they love everything about it". When asked to expand, the 
participants appreciated how hands on the service is, how carryover was easier because they had "done it as opposed to just being shown it", and how telehealth improved access to care. One caregiver expressed that telehealth has been beneficial because it supports the everyday routines of the family and it allows their child to feel more comfortable and more engaged at home, compared to traveling to an in-person facility.

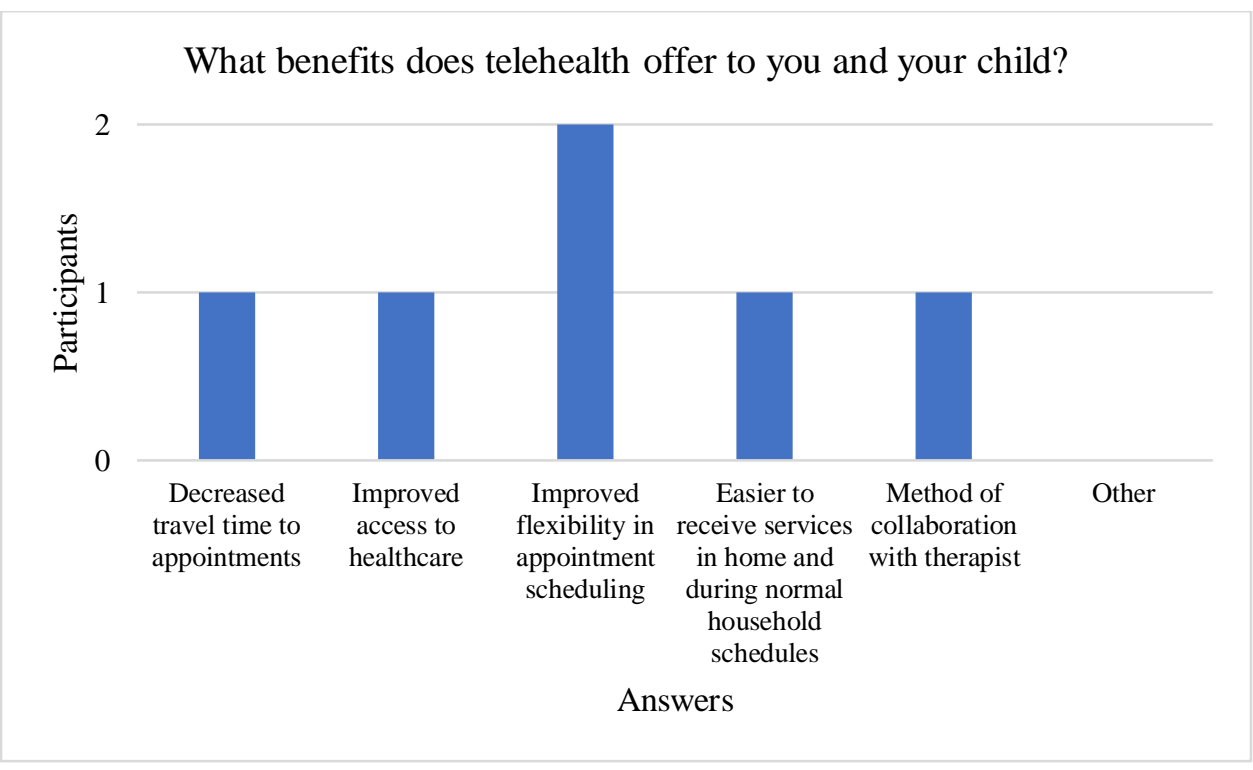

Figure 5. Survey answers from caregivers with telehealth experience regarding benefits telehealth offered their family.

The two participants were optimistic about the benefits that telehealth EI therapy offered them, their families, and their child. Both caregivers agreed that flexibility in scheduling was a benefit, while additional benefits that the families received included: decreased travel time, improved access to healthcare, easier to receive services in the home and during normal family routines and schedules, and the method of collaboration and coaching with the therapist was a positive experience. 


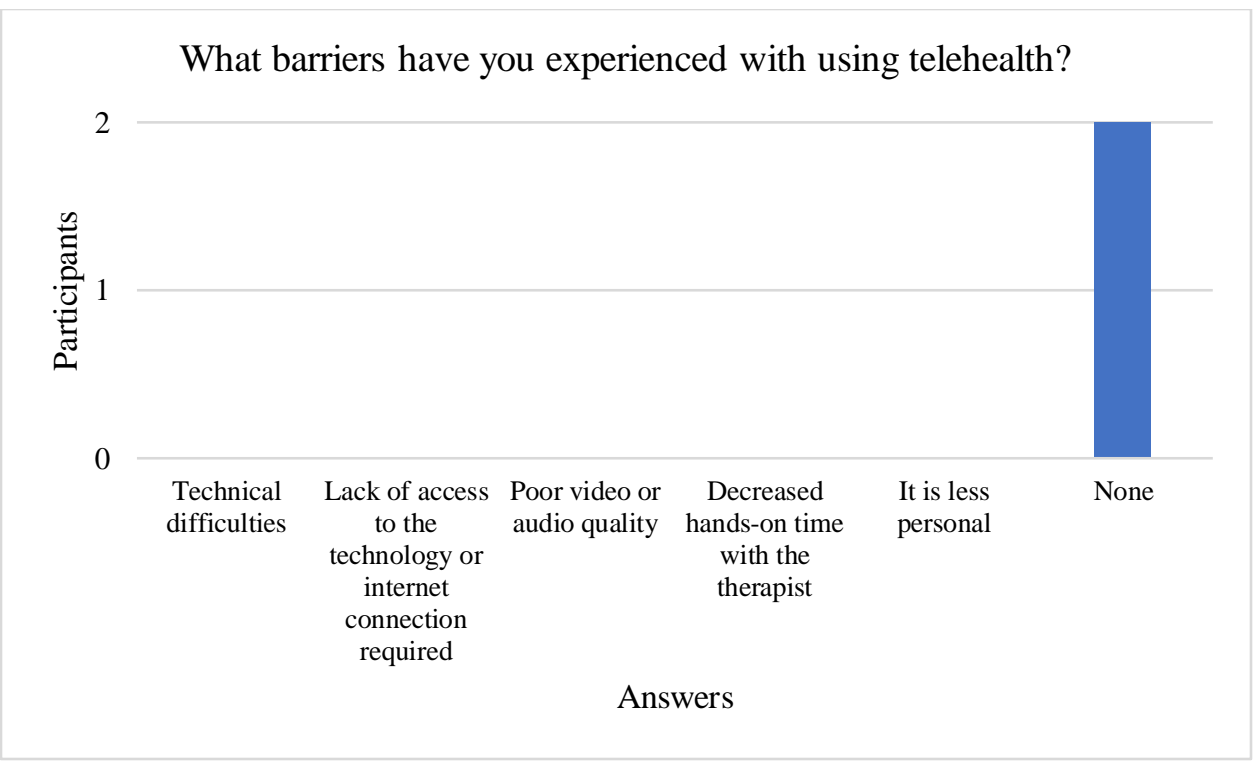

Figure 6. Survey answers from caregivers with telehealth experience regarding barriers of telehealth as a service delivery model.

Both participants felt that telehealth provided great benefits and that it was a preferred method of care for their family and child's situation. No barriers or limitations were reported in their experiences with telehealth EI services.

Are you comfortable with carrying out the treatments with your child without the therapist in the same physical location?

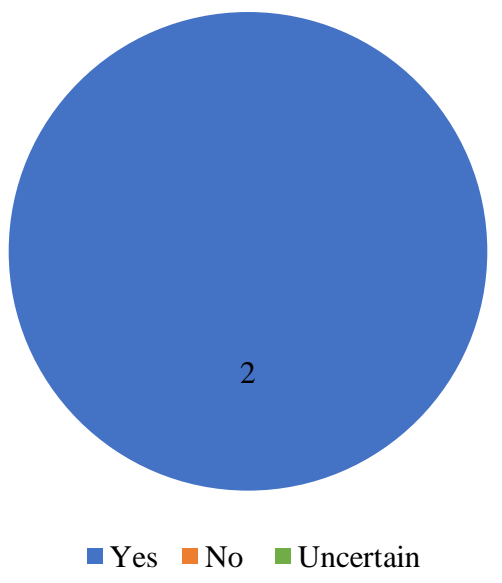

Figure 7. Number of caregivers with telehealth experience who felt comfortable with carrying out the treatments with the coaching of the therapist, who was located elsewhere. 
Both caregivers with telehealth experience were comfortable with carrying out treatments with their child and the remote coaching and support of the occupational therapist. One participant expanded on this, stating that this method of treatment is beneficial as a caregiver because it allows you to have full interactions with the child simultaneously with the direct feedback of the therapist. When asked about future telehealth involvement and whether they would recommend this service, both participants agreed that they would continue to use telehealth and that they would recommend this service to others. However, one participant would not recommend it to "parents who are reluctant participants" because telehealth requires the caregivers to be very hands-on and to know how to promote the carryover of services in everyday life.

The responses of caregivers with EI telehealth experience suggested that telehealth is a viable, effective, and beneficial model of therapy. The participants reported positive perceptions with the hands-on approach to therapy and felt comfortable and confident utilizing the coaching method of treatment. The responses to questions regarding the continuation of telehealth participation, as well as recommending the service for other families, suggested that all families could benefit, but some situations and caregiver approaches to parenting might cause a potential barrier. In addition to education on telehealth to healthcare providers and families, and information on how to develop a new program, there needs to be clarification of when this service model is appropriate. Case examples, as well as information on types of parenting approaches, as well as therapist intervention styles that are required for telehealth, will be important to identify. Similarly, education on program development should include information on communication styles and tools required for this service to be effective. For example, caregivers and therapists need to have internet connection, computer literacy, and a device that 
can run the online communication platform used for therapy sessions. In addition, the therapists delivering services via telehealth need to have good communication and coaching skills, while the caregivers on the other end should be comfortable with delivering hands-on therapy to their child with the remote support of the therapist.

\section{CHAPTER VI. Discussion}

\section{Limitations}

Throughout the research process, there were various limitations that affected the outcomes of the project. At the beginning, the researcher had difficulty getting permission to observe EI sessions with therapists. This was due to therapist availability, therapist comfort level with bringing the researcher into the homes of their clients, and the willingness of each family to allow the researcher to observe. With this age range, there were also many cancellations to therapy sessions. In addition, the researcher had challenges with getting willing participants. Some families that were contacted directly did not respond to emails or text messages and some therapists did not respond by sharing contact information or sharing the survey with families. This was due to the misconception regarding client confidentiality. In addition, timeliness of the response rate was delayed. Some participants and therapists required multiple methods of communication to encourage participation in the study. To improve this capstone project, the surveys to caregivers with and without telehealth experience could have been administered in their homes or during the therapy session. This could have helped to improve the number of participants and could further promote the overall communication with participants and therapists. Additionally, the survey could have been administered earlier in the timeline of the capstone project to allow for additional time for families to understand the project and to share 
their perceptions of telehealth. Interviews could have also taken place during the therapy session to encourage participation.

Although this study provided valuable information on the perspectives of caregivers, there are some limitations that can be addressed in future research. A larger sample size can be useful in establishing a representative sample; if the study continued for a longer period of time, the larger number of participants could be attained. In addition to a larger sample size, a more diverse group of participants can be advantageous in gathering a good representation of caregivers of children receiving early intervention services. This can include caregivers from different states and organizations. The participants were selected via convenience sampling; future research should use different methods. Lastly, additional information on the general demographic of pediatrics, that includes settings such as schools and outpatient clinics, can be beneficial to developing telehealth programs in these additional settings.

\section{Future Research}

Future research regarding the clinical benefits of telehealth can help to support this service in early intervention and other populations and settings as well. For this service model to be further implemented, additional studies on the viability and effectiveness of telehealth needs to be conducted. Research on comparison of telehealth outcomes to in-home or in-person therapy outcomes will be important to demonstrate the efficacy of telehealth.

In addition, telehealth in emerging areas should be a focus of future research. This can help with outreach of services and the development of new programs. Research must be developed regarding starting a telehealth program and how to train therapists on implementing it in practice. This information will be important with program development, public awareness, and 
therapy outreach. Specific to early intervention, these trainings can include information on the coaching model and parent involvement in treatment.

As a continuation to this capstone project, developing a telehealth program at HM Systems can be a great addition to what therapy services are available currently at that facility. In addition, developing an education and training program for service providers and therapy practices would improve the awareness, acceptance, and utilization of telehealth. Improving the perceptions of service providers and knowledge on the viability of telehealth can ultimately spread awareness to families and clients in need.

\section{Implications for Occupational Therapy}

Telehealth is an emerging practice area in all settings, as well as with the EI population. However, it is a service model that has not been universally accepted by service providers and clients. Additional research on efficacy of telehealth compared to traditional methods of therapy will be required to support this service model. Awareness in terms of educating service providers on this as a viable option to care, as well as promoting awareness to the general public, will be necessary for the support of this service model in occupational therapy practice. In terms of the EI population, education on the family coaching approach in conjunction with telehealth will be necessary to promote family involvement and to support occupational outcomes of the child receiving therapy.

\section{Conclusion}

Telehealth, which utilizes information and communication technologies, allows a healthcare provider to deliver services to clients remotely (WFOT, 2014). Cason stated, "telehealth is not a distinct and separate intervention" (2014, p. 30). The telehealth service model can be utilized for a variety of populations and settings. This capstone project focused 
specifically on its use, in the early intervention, or children aged three years and younger, population (Cason et al., 2012). With this age group, the use of coaching is important to promote caregiver efficacy, caregiver involvement, and therapist collaboration in the growth of occupational performance and development of the child (Graham et al., 2013). Telehealth is a viable and effective service model in this setting; however, there are some barriers that have prevented telehealth from being fully accepted and utilized by service providers and families (Schaper \& Pervan, 2007).

This capstone project has shown that caregivers without telehealth experience are open to the idea of using this service model and that they recognize its ability to create opportunities for families. However, there is uncertainty regarding using telehealth for their own child and family. This perception is due to lack of awareness regarding telehealth and lack of information on its effectiveness compared to in-person care. The second group of participants were caregivers who have used telehealth for EI services. All responses were positive regarding benefits telehealth provided them and their child. Regarding the general acceptance of this service model, the participants reflected that it might not be appropriate for all families. Future research and advocacy will be important to promote the acceptance of telehealth for healthcare facilities, providers, and clients. Education on how to deliver telehealth services, required skills and resources, benefits and effectiveness of telehealth compared to traditional methods of intervention, and general awareness of telehealth being an additional option to care will be important to promote acceptance of this service model. There is great potential in telehealth as an option for care in the EI setting. When healthcare facilities, providers and clients understand that it is a viable option for therapy services, telehealth will begin to be utilized to its fullest potential. 


\section{References}

Ashburner, J., Vickerstaff, S., Beetge, J., \& Copley, J. (2016). Remote versus face-to-face delivery of early intervention programs for children with autism spectrum disorders: Perceptions of rural families and service providers. Research in Autism Spectrum Disorders, 1. https://doi.org/10.1016/j.rasd.2015.11.011

Baharav, E. \& Reiser, C. (2010). Using telepractice in parent training in early autism. Telemedicine and e-health. 16(6), 727-731. Retrieved from http://prxusa.lirn.net/login?url=http://search.ebscohost.com/login.aspx?direct= true $\& \mathrm{db}=$ edsgao $\& A N=$ edsgcl.234790078\&site=eds-live

Cason, J. (2014). Telehealth: A rapidly developing service delivery model for occupational therapy. International Journal of Telerehabilitation, 6(1), 29-36. doi:10.5195/ijt.2014.6148

Cason, J., Behl, D., \& Ringwalt, S. (2012). Overview of states' use of telehealth for the delivery of early intervention (IDEA part C) services. International Journal of Telerehabilitation, 4(2), 39-46. doi:10.5195/ijt.2012.6105

Cason, J., Hartmann, K., Jacobs, K., \& Richmond, T. (2013). Telehealth. American Journal of Occupational Therapy, 67, 69-90. doi:10.5014/ajot.2013.67S69

Gardner, K., Bundy, A., \& Dew, A. (2016). Perspectives of rural carers on benefits and barriers of receiving occupational therapy via Information and Communication Technologies. Australian Occupational Therapy Journal, 63, 117-122. Retrieved from https://doi-org.prx-usa.lirn.net/10.1111/1440-1630.12256 
Gorst, S. L., Armitage, C., Hawley, M. \& Coates, E. (2013). Exploring patient beliefs and perceptions about sustained use of telehealth. International Journal of Integrated Care, 13(7). Retrieved from https://doi-org.prx-usa.lirn.net/10.5334/ijic.1393

Graham, F., Rodger, S., \& Ziviani, J. (2013). Effectiveness of occupational performance coaching in improving children's and mothers' performance and mothers' selfcompetence. American Journal of Occupational Therapy, 67, 10-18. https://doi.org/10.5014/ajot.2013.004648

Irfanahemad, A. S., Nandakumar, B. S., \& Radhiki, K. (2018). Use of unified theory of acceptance and use of technology model for telemedicine services: An exploratory study. International Journal of Community Medicine and Public Health, 5(9), 4112-4118. doi : 10.18203/2394-6040.ijcmph20183604

Kairy, D., Lehoux, P., Vincent, C., Visintin, M. (2009). A systematic review of clinical outcomes, clinical process, healthcare utilization and costs associated with telerehabilitation. Disability and Rehabilitation, 31(6), 427- 447. doi:10.1080/09638280802062553

Kessler, D., \& Graham, F. (2015). The use of coaching in occupational therapy: An integrative review. Australian Occupational Therapy Journal, 3, 160-176. Retrieved from https://doi-org.prx- usa.lirn.net/10.1111/1440-1630.12175

Kielhofner G, Mallinson T, Forsyth K, \& Lai J. (2001). Psychometric properties of the second version of the Occupational performance history interview (OPHI-II). American Journal of Occupational Therapy, 55(3), 260-267. Retrieved from http://search.ebscohost.com/login.aspx?direct=true\&db=ccm\&AN=107060776\&site=eds -live 
Little, L. M., Wallisch, A., Pope, E., \& Dunn, W. (2018). Acceptability and cost comparison of a telehealth intervention for families of children with autism. Infants \& Young Children, 31, 275-286. Retrieved from http://prxusa.lirn.net/login?url=http://search.ebscohost.com/login.aspx?direct=true \&db= edsgin\&AN=edsgcl.560648317\&site=eds-live

Schaper, L. K., \& Pervan, G. P. (2007). ICT and OTs: A model of information and communication technology acceptance and utilization by occupational therapists. International Journal of Medical Informatics, 76(1), 212-221. https://doiorg.prx-usa.lirn.net/10.1016/j.ijmedinf.2006.05.028

Smith, T. (2019). Qualitative and quantitative research. Salem Press Encyclopedia. Retrieved from http://search.ebscohost.com/login.aspx?direct=true \&db=ers\&AN=89164394\&site= eds-live

World Federation of Occupational Therapy, (2014). World federation of occupational therapists' position statement on telehealth. International Journal of Telerehabilitation, 6(1), 37-40. doi:10.5195/ijt.2014.6153

Zylstra, S. E. (2013). Evidence for the use of telehealth in pediatric occupational therapy. Journal of Occupational Therapy, Schools, and Early Intervention, 6, 326-355. https://doi. org/10.1080/19411243.2013.860765 


\section{Appendix A: Script for Recruitment and Participant Outreach}

\section{Email to Therapists}

Hello, My name is Rebecca Johnston, and I am an occupational therapy student at University of St. Augustine. I am conducting research with caregivers of children receiving EI services who have no experience with telehealth, as well as caregivers with telehealth experience. The purpose of this project is to investigate the perspectives of caregivers on this service model, and to identify strengths and challenges of telehealth for future programs to implement. In addition, we hope this project can help to educate service providers and the general public on telehealth.

In the attached document is a description of the study, as well as a link to participate in a fifteenminute survey. I would greatly appreciate it if you could forward this information to willing families who would be interested to participate. If you have further questions, please email r.johnston@usa.edu. Thank you for your time.

Best,

Rebecca Johnston, OTD/s

University of St. Augustine, San Marcos

\section{Attachment for Caregivers with Telehealth Experience}

To whom it may concern, My name is Rebecca Johnston, and I am an occupational therapy student at University of St. Augustine. I am conducting research on the perspectives of caregivers who have participated in an early intervention program using telehealth. The purpose of this project is to identify strengths and challenges of telehealth for future programs to implement. In addition, we hope this project can help to educate therapists and the general public on telehealth.

I would greatly appreciate if you could fill out the attached fifteen-minute survey regarding your experiences and thoughts on telehealth. Your completion of this anonymous survey provides consent to participate in this research study. Your input is very important to us, and we greatly appreciate your participation. https://docs.google.com/forms/d/e/1FAIpQLSfMGf4CTTxuIQISan0e6padDhBmzPTMYlr54BU vu3APfXBcUg/formResponse

In addition, if you would like to participate in a thirty-minute interview regarding your experiences with telehealth, please email r.johnston@usa.edu and we can set up a time that works best for you. Thank you for your time!

Sincerely,

Rebecca Johnston, OTD/s

University of St. Augustine, San Marcos 


\section{$\underline{\text { Attachment for Caregivers without Telehealth Experience }}$}

To whom it may concern,

My name is Rebecca Johnston, and I am an occupational therapy student at University of St. Augustine. I am conducting research on the perspectives of caregivers who have participated in an early intervention program, and who have no experience with telehealth. The purpose of this project is to investigate the perspectives of caregivers on this service model, and to identify strengths and challenges of telehealth for future programs to implement. In addition, we hope this project can help to educate service providers and the general public on telehealth.

I would greatly appreciate if you could fill out the attached fifteen minute survey regarding your perspective and thoughts on telehealth. Your completion of this anonymous survey provides consent to participate in this research study. Your input is very important to us, and we greatly appreciate your participation. Thank you for your time! https://docs.google.com/forms/d/e/1FAIpQLSdJh-pnC1Zhkckz40104QHqMDBOO3QpRzts9uA2eJrGIdETQ/formResponse

Sincerely,

Rebecca Johnston, OTD/s

University of St. Augustine, San Marcos 


\section{Text Message to Families}

\section{Hello!}

This is Rebecca Johnston and I am an occupational therapy student who observed , the occupational therapist. I want to thank you for allowing me to join; I learned a lot from the experience and appreciate your willingness to let me observe. For my doctorate capstone project, I am investigating perceptions of caregivers regarding telehealth. Attached is a link to an anonymous survey that should take 10-15 minutes. I would greatly appreciate your participation, and value your experiences and thoughts on this subject. If you have any questions, feel free to give me a text or call! Thank you and have a great day! https://docs.google.com/forms/d/e/1FAIpQLSdJh-pnC1Zhkckz40104QHqMDBOO3QpRzts9uA2eJrGIdETQ/formResponse 


\section{Emails to Families}

\section{Caregivers with Telehealth Experience}

To whom it may concern, My name is Rebecca Johnston, and I am an occupational therapy student at University of St. Augustine. I am conducting research on the perspectives of caregivers who have participated in an early intervention program using telehealth. The purpose of this project is to identify strengths and challenges of telehealth for future programs to implement. In addition, we hope this project can help to educate therapists and the general public on telehealth.

I would greatly appreciate if you could fill out the attached fifteen-minute survey regarding your experiences and thoughts on telehealth. Your completion of this anonymous survey provides consent to participate in this research study. Your input is very important to us, and we greatly appreciate your participation. https://docs.google.com/forms/d/e/1FAIpQLSfMGf4CTTxuIQISan0e6padDhBmzPTMYlr54BU vu3APfXBcUg/formResponse

In addition, if you would like to participate in a thirty-minute interview regarding your experiences with telehealth, please email r.johnston@usa.edu and we can set up a time that works best for you. Thank you for your time!

Sincerely,

Rebecca Johnston, OTD/s

University of St. Augustine, San Marcos

\section{Caregivers without Telehealth Experience}

To whom it may concern, My name is Rebecca Johnston, and I am an occupational therapy student at University of St. Augustine. I am conducting research on the perspectives of caregivers who have participated in an early intervention program, and who have no experience with telehealth. The purpose of this project is to investigate the perspectives of caregivers on this service model, and to identify strengths and challenges of telehealth for future programs to implement. In addition, we hope this project can help to educate service providers and the general public on telehealth.

I would greatly appreciate if you could fill out the attached fifteen-minute survey regarding your perspective and thoughts on telehealth. Your completion of this anonymous survey provides consent to participate in this research study. Your input is very important to us, and we greatly appreciate your participation. Thank you for your time! https://docs.google.com/forms/d/e/1FAIpQLSdJh-pnC1Zhkckz40104QHqMDBOO3QpRzts9uA2eJrGIdETQ/formResponse

Sincerely, Rebecca Johnston, OTD/s University of St. Augustine, San Marcos 


\section{Facebook Forum}

Hello!

My name is Rebecca Johnston and I am an occupational therapy doctorate student at University of St. Augustine in San Marcos, CA. For my capstone project, I am investigating the experiences and perceptions of caregivers, with children who are receiving early intervention services, regarding telehealth. The purpose of this project is to investigate the perspectives of caregivers on this service model, and to identify strengths and challenges of telehealth for future programs to implement. In addition, we hope this project can help to educate service providers and the general public on telehealth.

I plan to have families take an anonymous, fifteen-minute survey regarding their thoughts on telehealth. Both caregivers who have used telehealth for early intervention services, as well as those who have never used telehealth for early intervention services, are welcome to take the appropriate survey. I would greatly appreciate it if you could share this information and the attached links to willing families who would be interested to participate. If you have further questions, please contact me at r.johnston@usa.edu. Thank you for your time!

\section{Caregivers who have used telehealth:}

https://docs.google.com/forms/d/e/1FAIpQLSfMGf4CTTxuIQISan0e6padDhBmzPTMYlr54BU vu3APfXBcUg/formResponse

Caregivers who have not used telehealth: https://docs.google.com/forms/d/e/1FAIpQLSdJh-pnC1Zhkckz40104QHqMDBOO3QpRzts9uA2eJrGIdETQ/formResponse

Best,

Rebecca Johnston, OTD/s

University of St. Augustine, San Marcos 


\section{Facebook Forum "EI Support and Share"}

Hello! My name is Rebecca Johnston and I am an occupational therapy doctorate student at University of St. Augustine in San Marcos, CA. For my capstone project, I am investigating the experiences and perceptions of caregivers, with children who are receiving early intervention services, regarding telehealth. The purpose of this project is to investigate the perspectives of caregivers on this service model, and to identify strengths and challenges of telehealth for future programs to implement. In addition, we hope this project can help to educate service providers and the general public on telehealth.

I plan to have families take an anonymous, fifteen-minute survey regarding their thoughts on telehealth. Both caregivers who have used telehealth for early intervention services, as well as those who have never used telehealth for early intervention services, are welcome to take the appropriate survey. If you would like to participate, I would greatly appreciate your input! If you have further questions, please contact me at r.johnston@ usa.edu. Thank you for your time!

\section{Caregivers who have used telehealth:}

https://docs.google.com/forms/d/e/1FAIpQLSfMGf4CTTxuIQISan0e6padDhBmzPTMYlr54BU vu3APfXBcUg/formResponse

\section{Caregivers who have not used telehealth:}

https://docs.google.com/forms/d/e/1FAIpQLSdJh-pnC1Zhkckz40104QHqMDBOO3QpRzts9uA2eJrGIdETQ/formResponse

Best,

Rebecca Johnston, OTD/s

University of St. Augustine, San Marcos 


\section{Appendix B: Survey Questions- Caregivers with Telehealth Experience}

Your engagement in this survey provides informed consent to participate in this study regarding caregiver perspectives of telehealth. Your experiences and input are important to us- please answer the questions to your best ability. Thank you for your participation!

1. Select "yes" if you consent to participate in this study.
a. Yes

2. How far of a commute do you have to reach your medical provider?
a. 10-20 minutes
b. 30-40 minutes
c. 50-60 minutes
d. 1+ hours
e. Other

3. What state do you live in?

4. How old is your child, who is receiving therapy services, in months?

5. What therapy services does your child receive? Select all that apply.
a. Occupational Therapy
b. Physical Therapy
c. Speech Therapy
d. Other

6. How long has your child received therapy services?
a. Less than 1 month
b. 1-3 months
c. 4-6 months
d. 7-9 months
e. 10-12 months
f. 1+ years
g. Other

7. How long has your child been receiving therapy services via telehealth?

8. Approximately what percentage of your child's therapy sessions are delivered by telehealth?
a. $0-25 \%$
b. $26-50 \%$
c. $51-75 \%$
d. $76-100 \%$
e. Other 
9. What are your perceptions of telehealth? Select all that apply.
a. I will continue to use it
b. There are minor challenges
c. There are major challenges
d. I dislike it
e. Uncertain
f. Other

10. Please explain your answer to the previous question.

11. What benefits does telehealth offer to you and your child? Select all that apply. Please explain your answer.
a. Decreased travel time to appointments
b. Improved access to healthcare
c. Improved flexibility in appointment scheduling
d. Easier to receive services in home and during normal household schedules
e. Method of collaboration with therapist
f. None
g. Other

12. What barriers have you experienced with using telehealth? Select all that apply. Please explain your answer.
a. Technical difficulties
b. Lack of access to the technology or internet connection required
c. Poor video or audio quality
d. Decreased hands-on time with the therapist
e. It is less personal
f. None
g. Other

13. What do you think of the online interaction with the therapist? Please explain.
a. I like it
b. I dislike it
c. Uncertain
d. Other

14. Are you comfortable with carrying out the treatments with your child without the therapist in the same physical location? Please explain.
a. Yes
b. No
c. Uncertain
d. Other 
15. Will you use telehealth again in the future? Please explain.
a. Yes
b. No
c. Uncertain
d. Other

16. Would you recommend telehealth to other families?
a. Yes
b. No
c. Uncertain
d. Other

17. Please describe any additional comments, questions, or concerns regarding your experiences with telehealth. 


\section{Appendix C: Survey Questions- Caregivers without Telehealth Experience}

Your engagement in this survey provides informed consent to participate in this study regarding caregiver perspectives of telehealth. Your experiences and input are important to us- please answer the questions to your best ability. Thank you for your participation!

1. Select "yes" if you consent to participate in this study.
a. Yes

2. How far of a commute do you have to reach your medical provider?
a. 10-20 minutes
b. 30-40 minutes
c. 50-60 minutes
d. $1+$ hours
e. Other

3. What state do you live in?

4. How old is your child, who is receiving therapy services, in months?

5. What therapy services does your child receive? Select all that apply.
a. Occupational Therapy
b. Physical Therapy
c. Speech Therapy
d. Other

6. How long has your child received therapy services?
a. Less than 1 month
b. 1-3 months
c. 4-6 months
d. 7-9 months
e. 10-12 months
f. 1+ years
g. Other

7. Are you familiar with telehealth?
a. Yes
b. No
c. Other 
8. Telehealth allows the therapist to provide services to a child and family when they are not in the same location through the use of a videoconferencing platform (i.e. Skype, Zoom, FaceTime). What are your thoughts on using telehealth for you and your child?

a. I will look for telehealth services my child and I can participate in

b. I am interested to learn more

c. It might work for other families, but not for me

d. I am not interested

e. Uncertain

f. Other

9. Please explain your thoughts on telehealth.

10. What benefits do you think telehealth offer you and your child? Select all that apply. Please explain your answer.
a. Decreased travel time to appointments
b. Improved access to healthcare
c. Improved flexibility in appointment scheduling
d. Easier to receive services in home and during normal household schedules
e. Method of collaboration with therapist
f. None
g. Other

11. What do you think could be potential barriers to receiving telehealth? Select all that apply. Please explain your answer.
a. Technical difficulties
b. Lack of access to the technology or internet connection required
c. Poor video or audio quality
d. Decreased hands-on time with the therapist
e. It is less personal
f. None
g. Other

12. Do you think you would feel more engaged in therapy sessions using telehealth? Please explain.
a. Yes
b. No
c. Uncertain
d. Other

13. Do you know of any pediatric services near you that use telehealth?
a. Yes
b. No
c. Uncertain
d. Other 
14. Would you be interested to try telehealth services for your child?
a. Yes
b. No
c. Uncertain
d. Other

15. Please explain your answer to the previous question.

16. Please describe any additional comments or questions regarding your perceptions of telehealth. 


\section{Appendix D: Interview Questions- Caregivers with Telehealth Experience}

Hi! My name is Rebecca and I am an OT student. It is so nice to meet you, I really appreciate your time and participation for this study. My project will navigate the experiences of caregivers regarding telehealth as a service model. The study will help to educate service providers and potential clients regarding using telehealth as a service delivery. It will also identify strengths and solutions for future telehealth programs to incorporate, and it can help to advocate for the service so more individuals can gain access to care.

The point of the interview is to gather narratives from participants to understand their perspectives in their own words and to find commonalities. To help improve the documentation for the final analysis of the information, I was hoping to audio record this interview. The audio will transcribed for the data to be analyzed and the recording will be deleted once this process is complete. This is completely confidential and no names will be included in the study. Do you grant permission for me to make an audio recording of this conversation?

Okay, great. Thank you. Let's get started!

1. How far of a commute do you have to reach your medical provider?

2. How old is your child who is receiving therapy services?

3. What therapy services is your child currently receiving?

4. How long has your child received therapy services?

5. How long have you been using telehealth for therapy?

6. What percentage of your child's therapy sessions are delivered by telehealth?

7. In your own words, what are the benefits of telehealth that you and your child received?

8. In your own words, what are the challenges of telehealth that you experienced? Why?

9. How does telehealth compare to in-person health care, whether it is occupational therapy related or not (i.e. doctor's office)?

10. What suggestions do you have to improve this service?

11. What should future telehealth programs continue to do or change?

12. In your opinion, why might service providers or clients not want to engage in telehealth?

13. Would you recommend this service to others? And would you continue to use it?

14. Do you have any other comments? 


\section{Appendix E: Interview Questions- Caregivers Without Telehealth Experience}

1. How far of a commute do you have to reach your medical provider?

2. How old is your child who is receiving therapy services?

3. What therapy services is your child currently receiving?

4. How long has your child received therapy services?

5. Have you heard of telehealth before? What do you know about telehealth?

If they have no knowledge of telehealth, offer a brief description of the service and how it applies to early intervention.

6. What are your perceived benefits of telehealth?

7. Do you think this service delivery would benefit your child/family?

8. What are your perceived challenges of telehealth?

9. Would you ever try telehealth? Why/why not? 
Appendix F: San Diego Regional Center PowerPoint Presentation and Handouts

A Telehealth Introduction for Service Coordinators

...

Taylor Corey, OTD/S

Rebecca Johnston, OTD/S

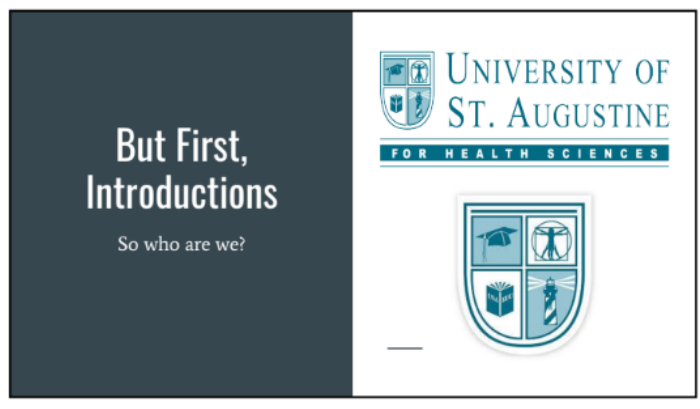

Learning Objectives

$\star$ Understand the use of telehealth as a service delivery model

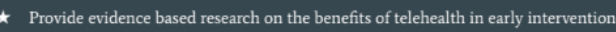

$\star \quad$ Introduce the Coaching Model

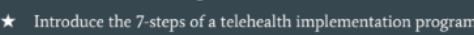

$\star$ What are the needs at HM Systems and how telehealth can benefit

$\star$ Overview of therapist perspectives and caregiver perspectives of telehealth based on our capstone projects
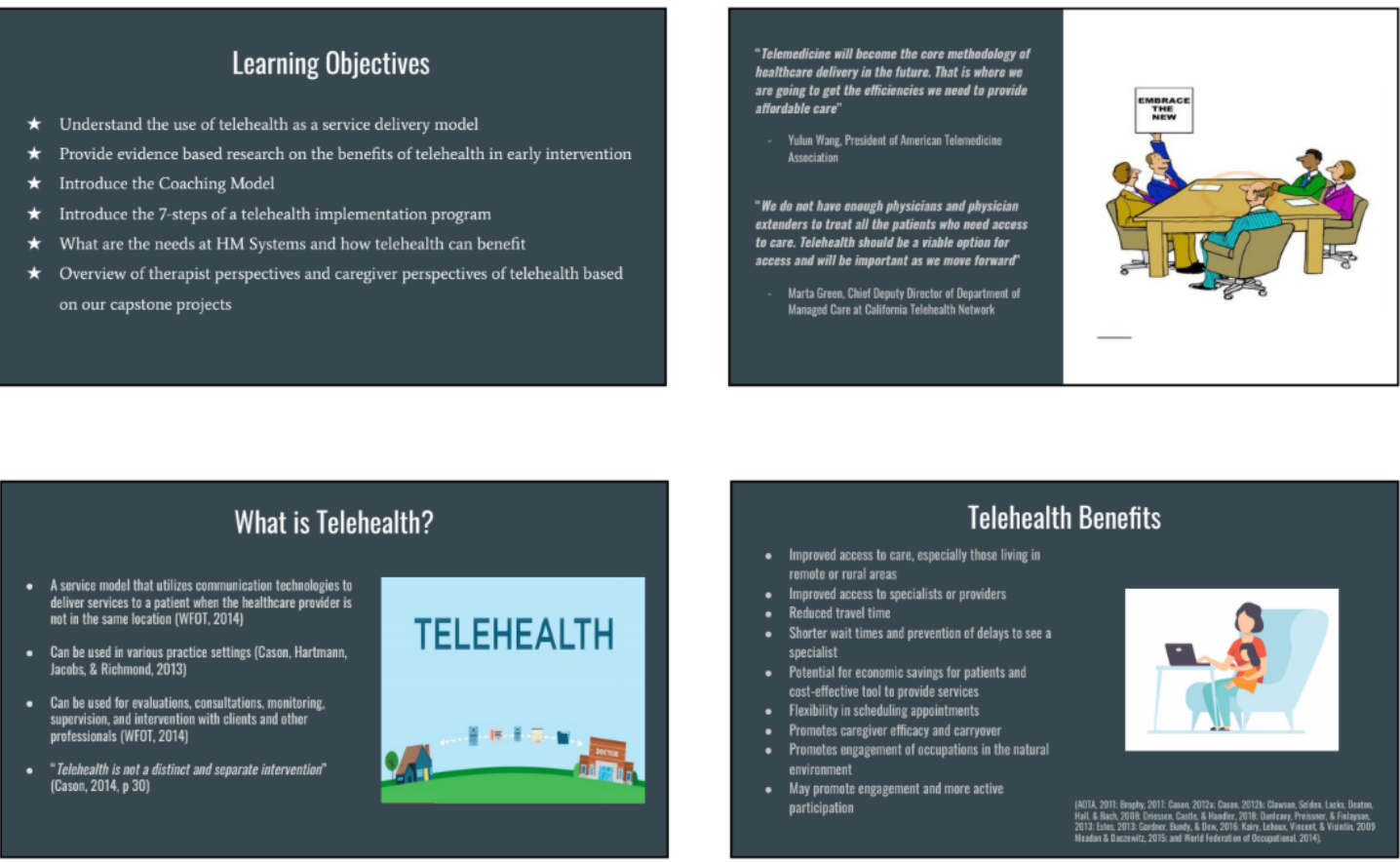

Telehealth Barriers

- Technology challenges

- Lack of access to computer or smartphone

Need for computer literacy

Apprehension by practitioners and clients

Privacy and security concerns

Less personal

- Lack of hands-on treatment for clients that may require this type of approach (i.e: NDT, PAMs

- Concerns relating to the client-practitioner therapeutic relationship

- State licensure issues

- Need for more rigorous research to help support the use of telehealth

Why Telehealth in Early Intervention?

- Telehealth is recognized for OT, PT, and ST as an appropriate and effective model to provide early intervention services

- Increases participation of child and family

- Care can take place in the natural environment of the child, and during normal routines of the family (i.e. feeding during regular mealtime)

of the family (i.e. feeding during regular mealime)

Utilizes the coaching model, which helps to empower families with the care of thei child 

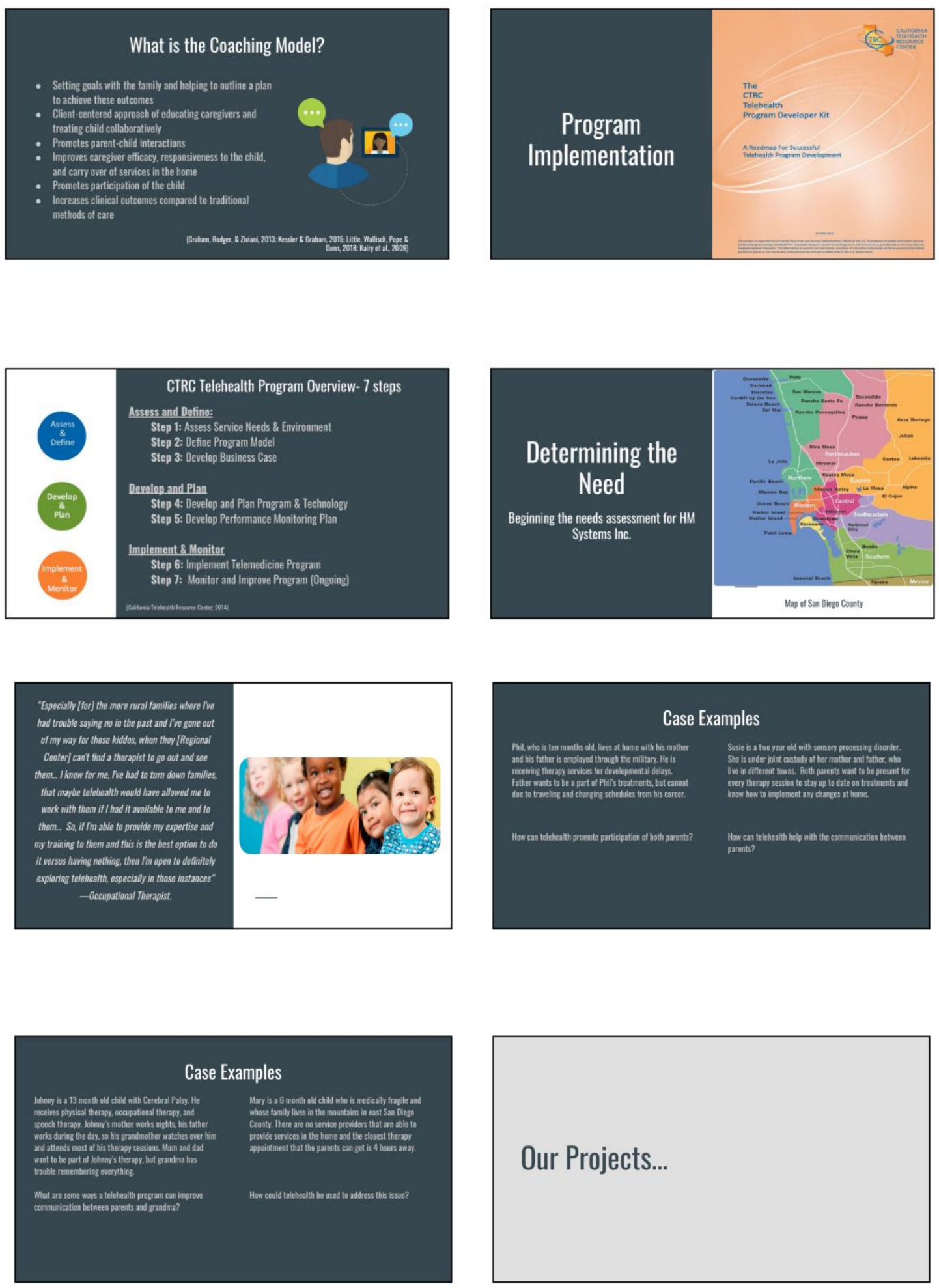
Most Reported Benefits- Therapist's Perspectives of Telehealth

Proviters Wha Hare Used Telehtoalth: Proviters tha Hine Hot Used Trelohentlt: Improve accessibility of senices/care (89\%) May promate mare enegement and sctive participation ty the clicati/carogiver (63\%) Preventian of delays to see a specialist (38\%)

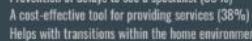
(24\%) Mingzite cancellations $(19 \%)$ . Rediced travel time $70 \%$ Provention of debibs to see a specialat (160\%) May promote more engagenent ind active participation by the client/carcegur (37\%) Tosl for retarnalis cansulatations and screens (16\%)

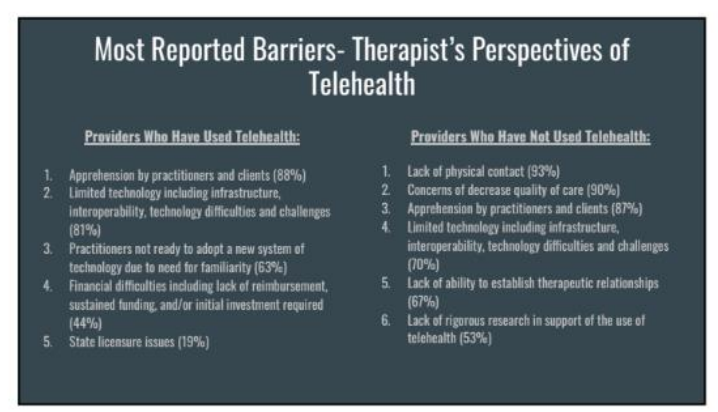

Most Reported Barriers- Caregiver's Perspectives of Telehealth Telehealth

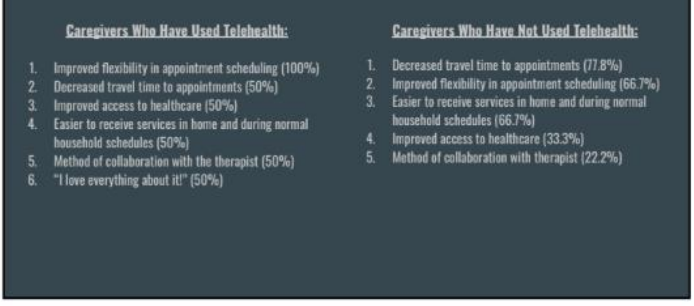

Gancegivers the Have Used Telchealth:

Nane (100\%)

Garesiners Whe Have Hot Used Telehenth: Decreased hands-on time with the therapist (88.9\%)

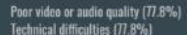
it is less personal (55.6\%) tack of acesss to the technibgy or the internet cannection requirad (333\%)

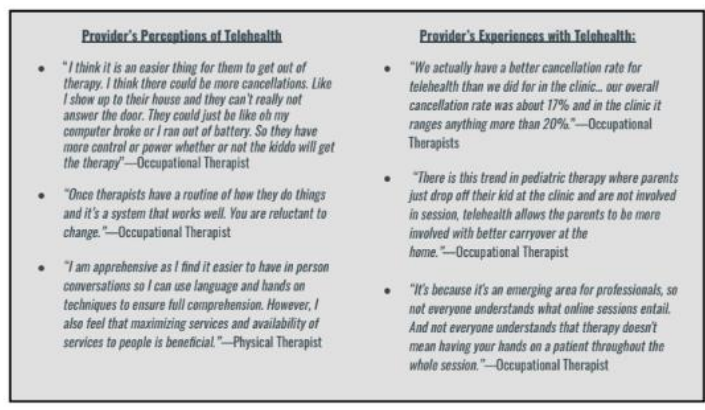

\begin{tabular}{|c|c|}
\hline 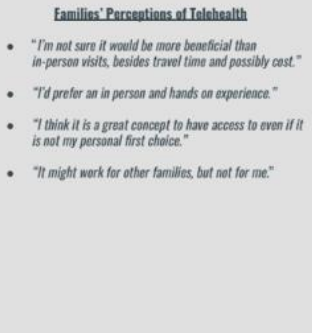 & 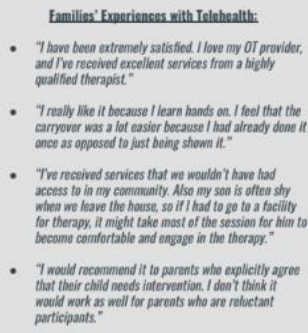 \\
\hline
\end{tabular}
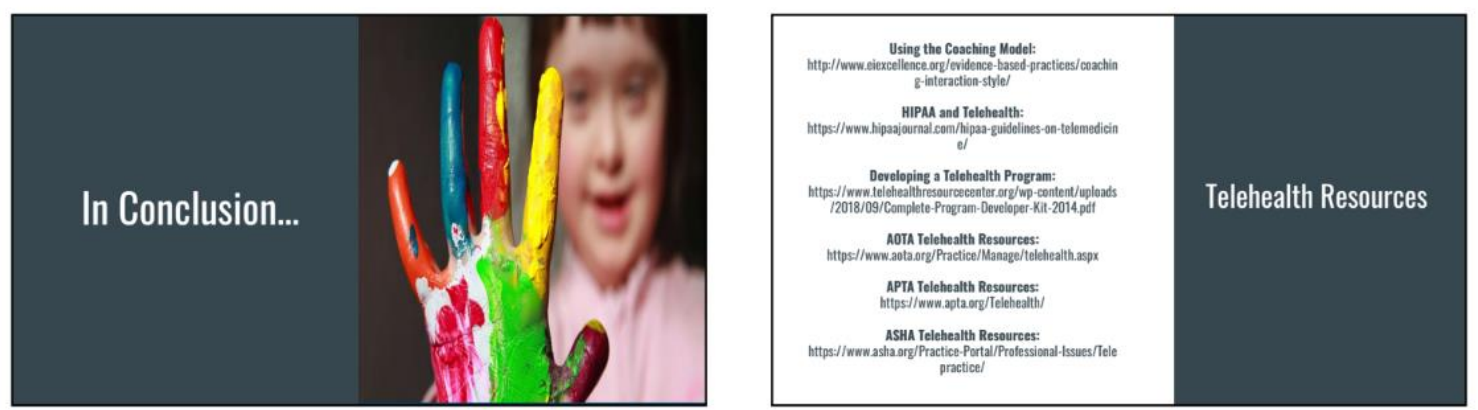

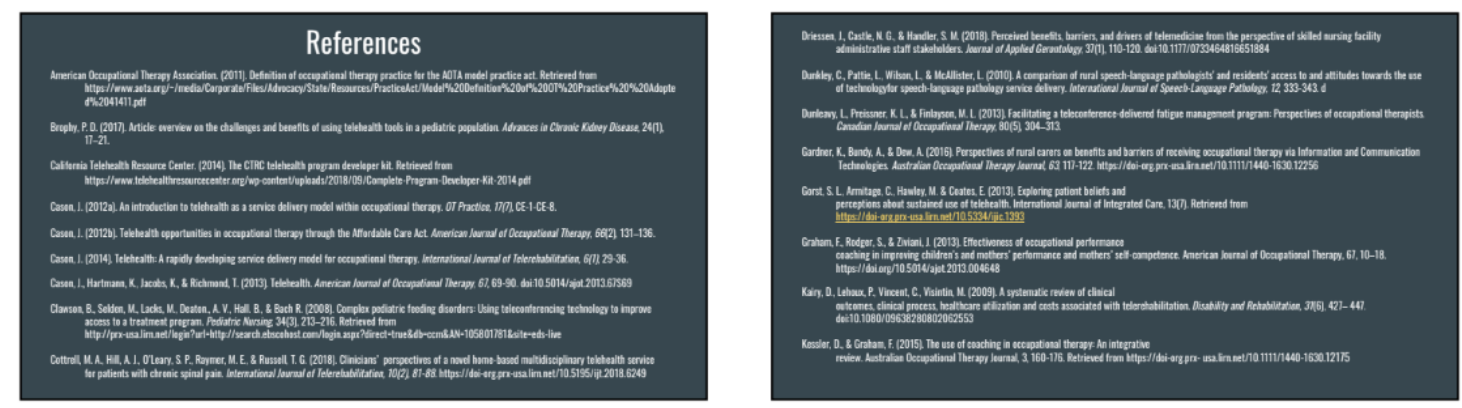

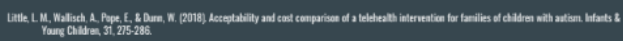

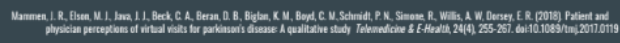

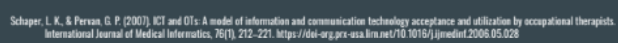

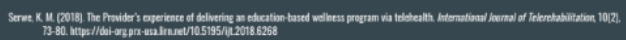

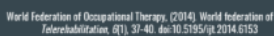

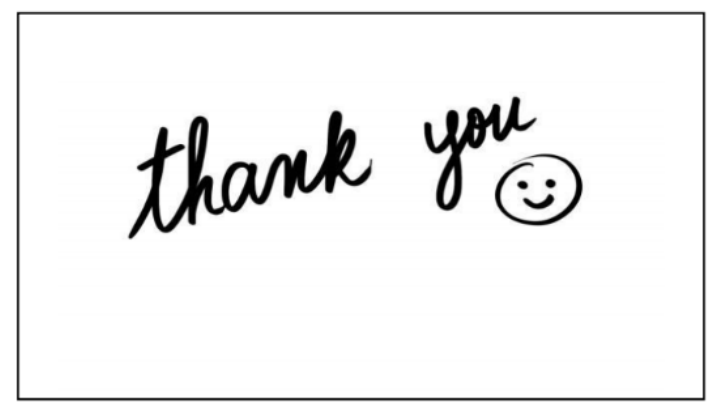

\section{Questions?}




\section{CTRC Telehealth Program Overview- 7 Steps}

\section{Assess \& Define}

Three steps support assessing the environment and defining the proposed program:

Step 1: Assess Service Needs \& Environment

- Assess service needs

- Identify potential telehealth opportunities

- Assess organizational readiness

Step 2: Define Program Model

- Consider the type of program that will meet needs

Step 3: Develop Business Case

- Determine the impact of the proposed telehealth program

\section{Develop \& Plan}

Two steps support fully defining the activities necessary for program implementation:

Step 4: Develop and Plan Program \& Technology

- Create a detailed project plan

Step 5: Develop Performance Monitoring Plan

- Define monitoring and evaluation mechanisms and program improvement process

\section{Implement \& Monitor}

The final two steps support implementation and ongoing monitoring:

Step 6: Implement Telemedicine Program

- Perform all the work required to implement the program

Step 7: Monitor and Improve Program (Ongoing)

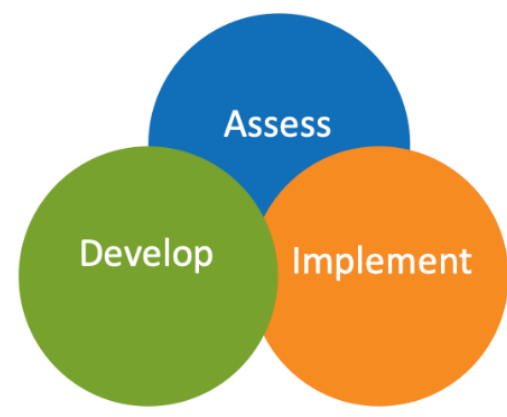

For more information:

California Telehealth Resource Center. (2014). The CTRC telehealth program developer kit. Retrieved from https://www.telehealthresourcecenter.org/wpcontent/uploads/2018/09/Complete-Program-Developer-Kit-2014.pdf 


\section{Appendix G: HM Systems PowerPoint Presentation and Handouts}

A Telehealth Introduction for Service Providers

$\bullet$

Taylor Corey, OTD/s

Rebecca Johnston, OTD/s

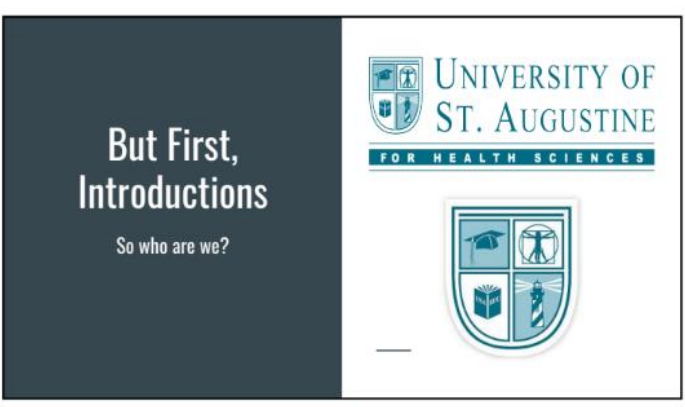

\section{Learning Objectives}

Understand the use of telehealth as a service delivery model

$\star$ Provide evidence based research on the benefits of telehealth in early intervention

$\star$ Introduce the Coaching Model

$\star$ Overview of therapist perspectives and caregivers perspectives of telehealth based on our capstone projects

What do you think are the benefits of telehealth?

What do you think could be barriers of telehealth?
What is Telehealth?

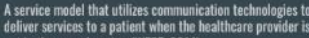

doliver services to a patient when the
not in the same location (WFOT, 2014)

Can be used in various prectice settings (Cason, Hartmann.

lacobs, \& Richnond, 2013)

- Can be used for evaluations, consultations, monitorine

professionals (Wfor, 2014)

- "Telehoulth is nota distinct and separate intervention"

TELEHEALTH

If is $\mathrm{r}^{-}-$
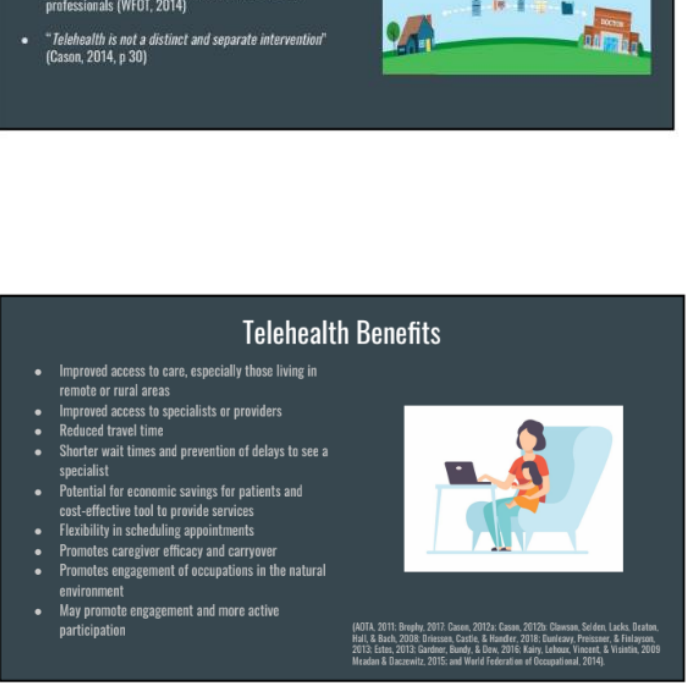

\section{Telehealth Barriers}

- Technology challenges

Lack of access to computer or smartphone

Need for computer literacy

Apprehension by practitioners and clients

Privacy and security concerns

Lack of physical contact

Less personal

Lack of hands-on treatment for clients that may require this type of approach (ie: NDT. PAMs

- Concerns relating to the client-practitioner therapeutic relationship

- State licensure issues

- Need for more rigorous research to help support the use of telehealth

- Personality

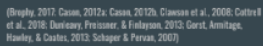



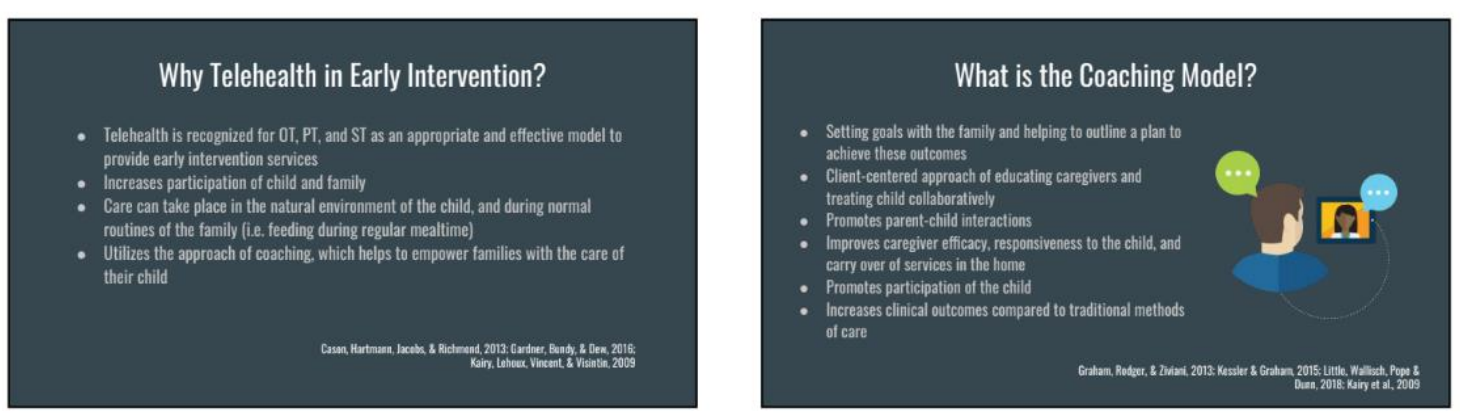

Are there any clients that you currently have or may have had in the past that you think would have benefited from telehealth?
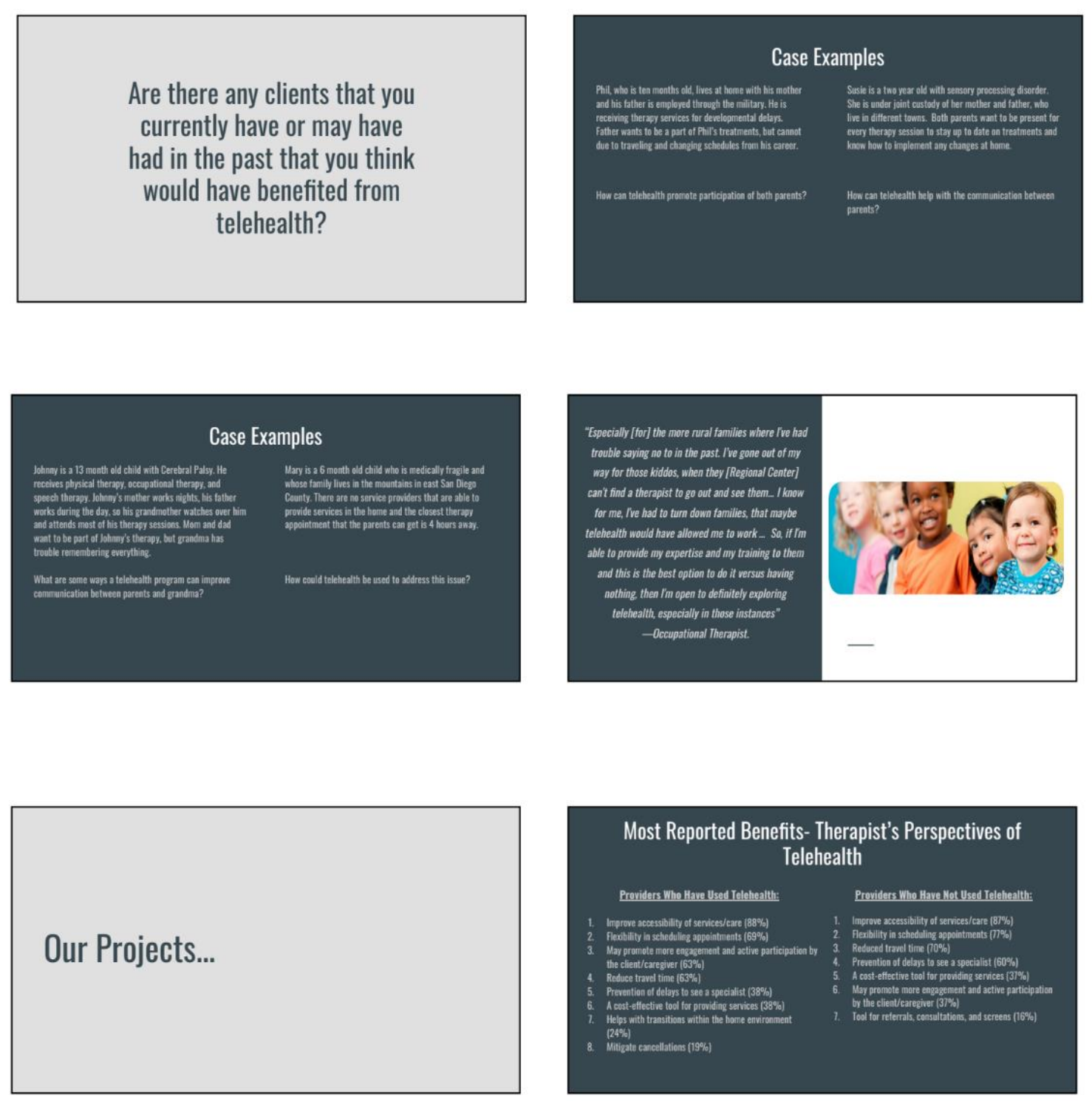

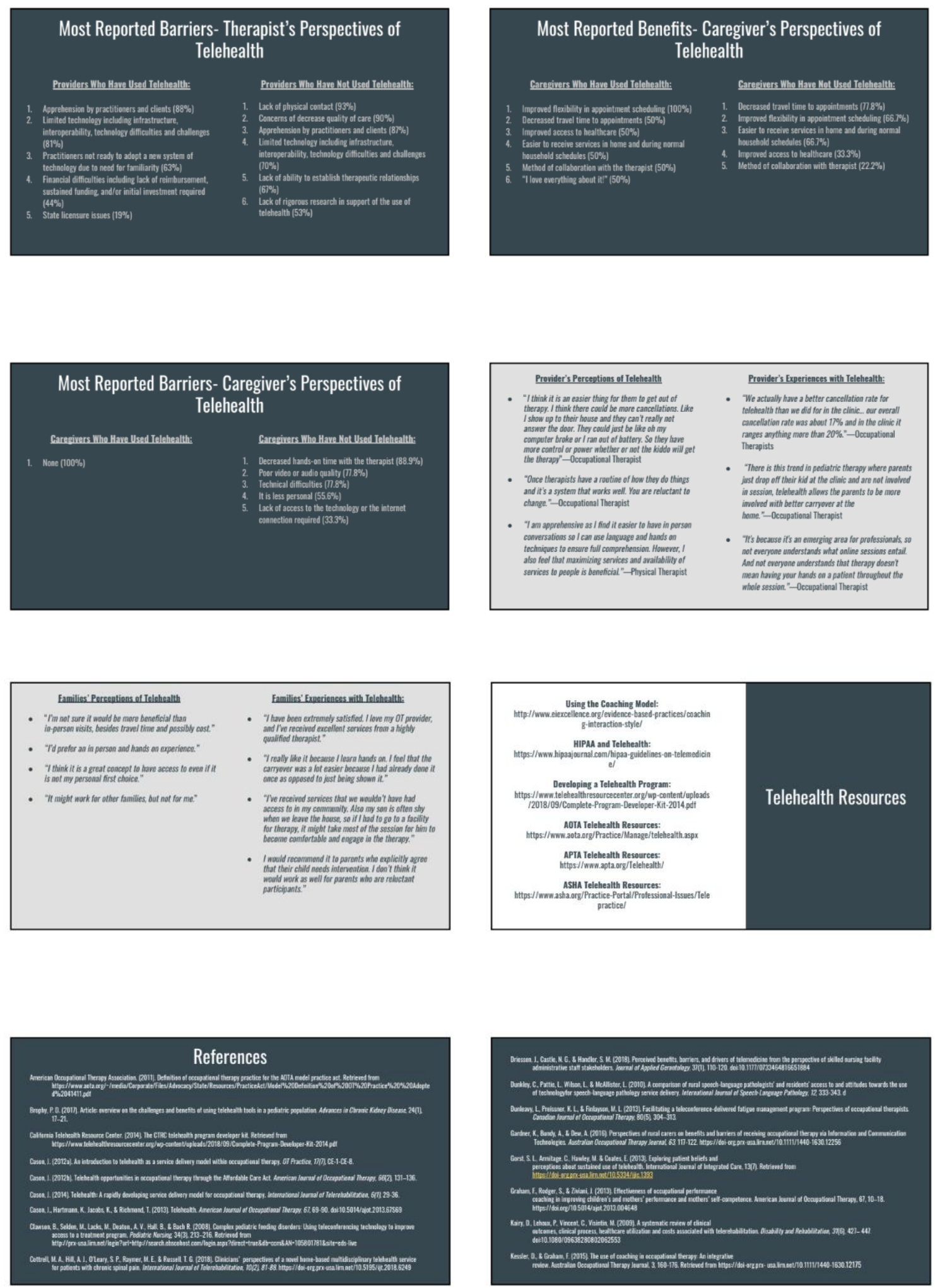

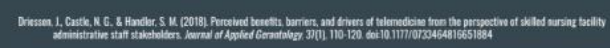

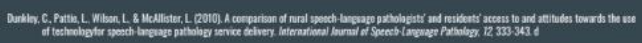

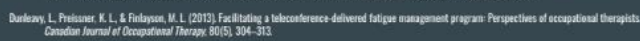

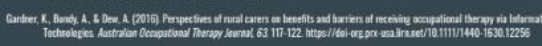

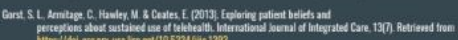

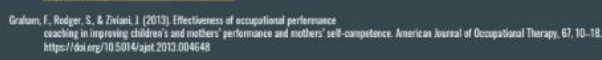

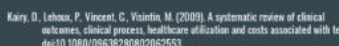

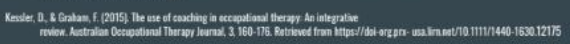



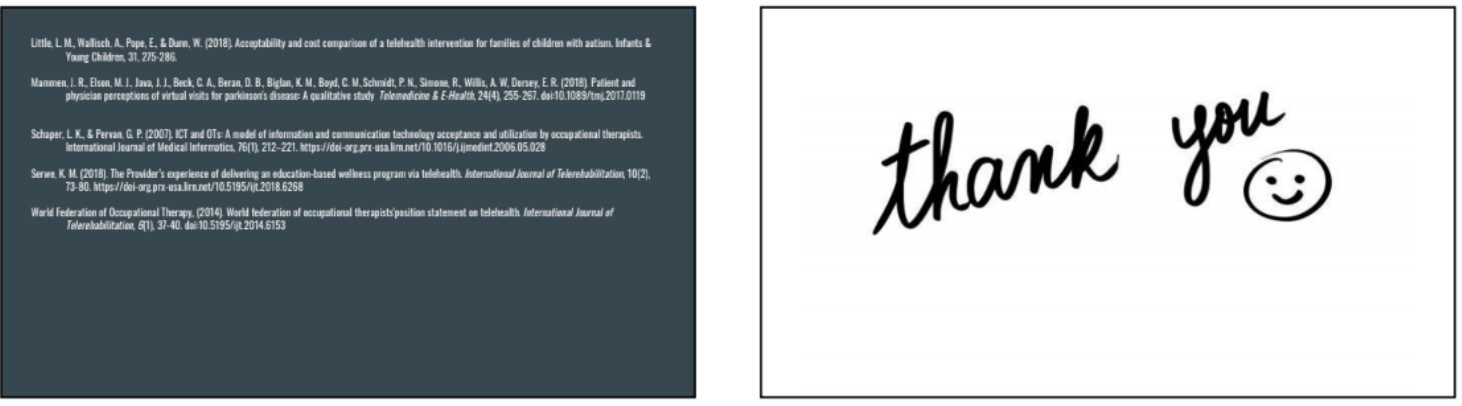

\section{Questions?}




\section{Case Examples for Telehealth in Early Intervention}

1. Phil, who is ten months old, lives at home with his mother and his father is employed through the military. He is receiving therapy services for developmental delays. Father wants to be a part of Phil's treatments, but cannot due to traveling and changing schedules from his career.

How can telehealth promote participation of both parents?

2. Susie is a two-year-old with sensory processing disorder. She is under joint custody of her mother and father, who live in different towns. Both parents want to be present for every therapy session to stay up to date on treatments and know how to implement any changes at home.

How can telehealth help with the communication between parents?

3. Johnny is a 13-month-old child with Cerebral Palsy. He receives physical therapy, occupational therapy, and speech therapy. Johnny's mother works nights, his father works during the day, so his grandmother watches over him and attends most of his therapy sessions. Mom and dad want to be part of Johnny's therapy, but grandma has trouble remembering everything.

What are some ways a telehealth program can improve communication between parents and grandma?

4. Mary is a 6-month-old child who is medically fragile and whose family lives in the mountains in east San Diego County. There are no service providers that are able to provide services in the home and the closest therapy appointment that the parents can get is 4 hours away.

How could telehealth be used to address this issue? 
